\title{
Spatial sensitivity analysis of snow cover data in a distributed rainfall-runoff model
}

\author{
T. Berezowski ${ }^{1,2}$, J. Nossent ${ }^{2}$, J. Chormański ${ }^{1}$, and O. Batelaan ${ }^{2,3}$ \\ ${ }^{1}$ Department of Hydraulic Engineering, Warsaw University of Life Sciences, Nowoursynowska 166, 02-787 Warsaw, Poland \\ ${ }^{2}$ Department of Hydrology and Hydraulic Engineering, Vrije Universiteit Brussel, Pleinlaan 2, 1050 Brussels, Belgium \\ ${ }^{3}$ School of the Environment, Flinders University, GP.O. Box 2100, Adelaide SA 5001, Australia \\ Correspondence to: T. Berezowski (t.berezowski@levis.sggw.pl)
}

Received: 17 September 2014 - Published in Hydrol. Earth Syst. Sci. Discuss.: 30 October 2014

Revised: 7 March 2015 - Accepted: 5 April 2015 - Published: 21 April 2015

\begin{abstract}
As the availability of spatially distributed data sets for distributed rainfall-runoff modelling is strongly increasing, more attention should be paid to the influence of the quality of the data on the calibration. While a lot of progress has been made on using distributed data in simulations of hydrological models, sensitivity of spatial data with respect to model results is not well understood. In this paper we develop a spatial sensitivity analysis method for spatial input data (snow cover fraction - SCF) for a distributed rainfall-runoff model to investigate when the model is differently subjected to SCF uncertainty in different zones of the model. The analysis was focussed on the relation between the SCF sensitivity and the physical and spatial parameters and processes of a distributed rainfall-runoff model. The methodology is tested for the Biebrza River catchment, Poland, for which a distributed WetSpa model is set up to simulate 2 years of daily runoff. The sensitivity analysis uses the Latin-Hypercube One-factor-At-a-Time (LH-OAT) algorithm, which employs different response functions for each spatial parameter representing a $4 \times 4 \mathrm{~km}$ snow zone. The results show that the spatial patterns of sensitivity can be easily interpreted by cooccurrence of different environmental factors such as geomorphology, soil texture, land use, precipitation and temperature. Moreover, the spatial pattern of sensitivity under different response functions is related to different spatial parameters and physical processes. The results clearly show that the LH-OAT algorithm is suitable for our spatial sensitivity analysis approach and that the SCF is spatially sensitive in the WetSpa model. The developed method can be easily applied to other models and other spatial data.
\end{abstract}

\section{Introduction}

Distributed hydrological models are developed to improve the simulation and analysis of physically based, spatially distributed hydrological processes. While more spatially distributed parameters and input data are becoming available for modelling, most attention is paid to the influence of the data on the quality of the calibration and to the capacity of models to reproduce measured output time series. Several researchers focussed on the effect of using distributed precipitation data in hydrological models. Obled et al. (1994) showed with a semi-distributed TOPMODEL (Beven et al., 1995) application that although the number of stations used to generate a rainfall field appeared to have an important impact on discharge simulation, the response of the model to changes in the rainfall field was marginal. Schuurmans and Bierkens (2007) used the fully distributed SIMGRO (Querner, 1997) model to analyze the effect of rainfall fields generated on the basis of rain gauge and radar data on discharge, soil moisture and groundwater heads. In their study, the distributed data outperformed lumped data in the simulation results. A similar study was conducted by $\mathrm{Fu}$ et al. (2011), who used the MIKE SHE model (Abbott et al., 1986). However, in this case a clear effect of rainfall distribution was visible only on groundwater head and recharge. In summary, the advantage of spatially distributed precipitation over lumped data may vary depending on the model, study area and processes under consideration. Nonetheless, the spatial aspect of model parameters, input data and the way they are implemented in models clearly is an important research issue. 
Several studies address classical sensitivity and uncertainty analysis methods to spatial data and parameters. An interesting stochastic uncertainty approach for spatial rainfall fields in the dynamic TOPMODEL (Beven and Freer, 2001) was presented by Younger et al. (2009). The results were obtained by dividing a catchment into homogeneous irregular zones in which the precipitation was randomly perturbed by large factors. Their study, however, focusses on the model output uncertainty rather than on quantification of spatial sources of uncertainty or spatial sensitivity.

Another study is presented by Stisen et al. (2011), who investigated whether the use of spatially distributed surface temperature data in an objective function can provide robust calibration and evaluation of the MIKE SHE model compared to a lumped simulation. The study used a spatial perturbation of parameters by random factors between 0.75 and 1.25 in a $2 \mathrm{~km}$ grid for the sensitivity analysis, but the results were not analyzed spatially. Thus no spatial pattern of sensitivity, showing which zones of the model are more vulnerable to uncertainty, was obtained.

Another spatial approach for sensitivity analysis was presented by Hostache et al. (2010). In their work a local, gradient method was applied to conduct a sensitivity analysis of the Manning coefficient in each computational node of a hydrodynamic model. This approach showed completely different sensitivity zonation than in the predefined land-use-based Manning coefficient classes used as a comparison scenario. This result stresses the importance of assessing the sensitivity in a spatially distributed way.

In this study, the various approaches of spatial sensitivity (or uncertainty) analysis presented above are compiled and extended in order to propose a method that would be generally applicable and thus would give a framework for inter-comparison of different models. Such a method would use a regular grid to quantify the spatial pattern of sensitivity as in Stisen et al. (2011); hence it differs from the irregular zonation in Younger et al. (2009). Furthermore, the perturbation of spatial input data in a general framework should be realized using a well-established algorithm, e.g. LatinHypercube One-factor-At-a-Time (LH-OAT) (van Griensven et al., 2006). This change would give a straightforward interpretation of the sensitivity. Similarly, Hostache et al. (2010) used a well-established gradient method for spatial sensitivity analysis. However, unlike the gradient method, LH-OAT provides global insight into sensitivity. Such a method would also allow one to quantify the sensitivity of spatial data with respect to the output and be able to explain the causes for the sensitivity patterns.

The main purpose of the application of spatial sensitivity analysis proposed in this study would be, after the Saltelli (2002) definition of sensitivity analysis, to quantify spatially the vulnerability of the model output to uncertainty of spatial input. Thus a result of this analysis would provide feedback, e.g. in regards to where in a model domain a modeler should focus more on the quality of input data and parameters. How- ever, the same method can be used for comprehensive spatial change (e.g. land-use change) analyses to show where the change (e.g. urbanization) would be least or most influencing the model output.

An important issue in this study is the selection of the hydrological model used to conduct the spatial sensitivity analysis. An option is the Water and Energy Transfer between Soil, Plants and Atmosphere (WetSpa) model (De Smedt et al., 2000; Liu and De Smedt, 2004) which has shown to have a high sensitivity with respect to runoff prediction when various scenarios of distributed impervious surfaces input data were tested (Chormański et al., 2008; Berezowski et al., 2012; Verbeiren et al., 2013). Moreover, the WetSpa model allows parametrization based on distributed snow data from a remote sensor (Berezowski et al., 2015).

Another issue is the selection of the input data used to conduct the spatial sensitivity analysis. A spatial data set that is frequently tested and easy to obtain is snow cover. Snow cover fraction (SCF [-]) or snow water equivalent remote sensing products are widely available from a number of sensors. The different available products vary widely in spatial resolution $(500 \mathrm{~m}$ to $25 \mathrm{~km}$ ), temporal resolution (sub-daily to monthly) and temporal coverage (the oldest time series starts in 1966, while new products are regularly announced). One of the most frequently used remote sensing snow products comes from the MODIS instrument (Hall et al., 2006). Several studies show different strategies with respect to how hydrological models can benefit from MODIS snow cover data. A popular approach is to derive snow depletion curves from MODIS SCF and use them in the Snowmelt Runoff Model (SRM) (Martinec, 1975). This approach is still popular and used in recent studies (Lee et al., 2005; Tekeli et al., 2005; Li and Williams, 2008; Butt and Bilal, 2011; Tahir et al., 2011; Bavera et al., 2012). However, the SRM studies are focussed mostly on the winter half-year and are limited to study sites where snowmelt processes are dominant. Another popular model which benefits from satellite-derived SCF is HBV (Sælthun, 1996), with a number of studies showing use of MODIS snow products (Udnaes et al., 2007; Parajka and Blöschl, 2008; Şorman et al., 2009). In the WetSpa model the MODIS snow products were used to evaluate spatial distribution of predicted snow cover (Zeinivand and De Smedt, 2010) and for analysing its skill for discharge simulation (Berezowski et al., 2015). The spatial sensitivity of model output to snow cover, despite its popularity as input data in distributed hydrological models, has not yet been evaluated.

The aim of this paper is to provide and test a methodology for a global spatial sensitivity analysis of SCF in a distributed rainfall-runoff model. The purpose of this analysis is to show whether the WetSpa model is spatially sensitive to SCF, i.e. to identify zones where the model output is most vulnerable to input uncertainty. An important point of the analysis is to explain the existing patterns of spatial sensitivity in function of physical and spatial parameters used and hydrological processes in the study area. For the remainder of the paper, the 
section "Methods" presents the spatially distributed rainfallrunoff model WetSpa, the study area, data and spatial sensitivity analysis. In "Results" the output of the spatial sensitivity analysis of SCF for the Biebrza River catchment is presented and described. The "Discussion" section presents the results in light of the hydrological processes occurring in the study area, but further applicability of the spatial sensitivity analysis method and the limitation of the method (e.g. computation time) are also provided. The final section "Conclusions" recaps the main findings of the study.

\section{Methods}

\subsection{Hydrological model}

The hydrological simulations in this study were conducted using the WetSpa model (De Smedt et al., 2000; Liu et al., 2003). The model divides a catchment into a regular grid with a specified dimension. In each grid cell, the water balance is simulated and the surface, interflow and groundwater discharge components are routed to the catchment outlet (Wang et al., 1996). Spatial parameters used to calculate the hydrological processes are obtained from land-use, soil and elevation input maps. Attribute tables based on literature data are linked to the maps and transformed to distributed physical values via a GIS preprocessing step (Chormański and Michałowski, 2011). Several studies have demonstrated that WetSpa and its steady-state version WetSpass (Batelaan and De Smedt, 2007) are suited to integrate distributed remote sensing input data in the simulation of the hydrological processes (Poelmans et al., 2010; Dujardin et al., 2011; Ampe et al., 2012; Chormański, 2012; Demarchi et al., 2012; Dams et al., 2013).

The model consists of the following storages: interception, depression, root zone, interflow and groundwater. Water transport between the storages is based on physical and empirical equations. Rainfall, temperature and potential evapotranspiration based on data from meteorological stations are made spatially explicit by use of Thiessen polygons, but a spatially distributed input form is also possible.

In the standard WetSpa version, snow accumulation is calculated based on precipitation and a threshold temperature $t_{0}\left({ }^{\circ} \mathrm{C}\right)$. When the temperature in a grid cell is $t\left({ }^{\circ} \mathrm{C}\right)$ and falls below $t_{0}$, precipitation is assumed to be snow. Snowmelt is calculated based on $t_{0}$, a degreeday coefficient $k_{\text {snow }}\left(\mathrm{mm}^{\circ} \mathrm{C}^{-1}\right.$ day $\left.^{-1}\right)$ and coefficient $k_{\text {rain }}$ $\left(\mathrm{mm} \mathrm{mm}{ }^{-1}{ }^{\circ} \mathrm{C}^{-1}\right.$ day $\left.^{-1}\right)$, reflecting the amount of snowmelt caused by rainfall $v_{\text {rain }}(\mathrm{mm})$. In this study SCF was obtained from MODIS snow products and used as input data. Thus, snow accumulation was not calculated but replaced with the input SCF, while the snowmelt amount $\left(v_{\mathrm{sm}}\right)(\mathrm{mm})$ per model time step $\delta_{\mathrm{t}}$ (day) is calculated as

$v_{\mathrm{sm}}=\operatorname{SCF}\left(k_{\text {snow }}\left(t-t_{0}\right)+k_{\text {rain }} v_{\text {rain }}\left(t-t_{0}\right)\right) \delta_{t}$.
This approach of calculating snowmelt based on SCF and snowmelt rate was proposed by Liston (1999). It allows us to obtain distributed $v_{\text {sm }}$ values weighted by SCF from grid cells where SCF $>0$. WetSpa is also capable of using an energy balance model for snowmelt calculation (Zeinivand and De Smedt, 2010); however, because of the higher demand on input data, this approach was not used.

Surface water routing is based on a geomorphological instantaneous unit hydrograph (IUH) (Liu et al., 2003). The IUH is calculated for a flow path starting in a grid cell and ending at the catchment outlet, i.e. each grid cell has its own IUH. Groundwater flow and interflow are calculated on a sub-catchment level based on a linear reservoir method and routed to the catchment outlet with the IUH. Comparison of the WetSpa performance with other distributed hydrological models can be found in the results of the DMIP2 project (Safari et al., 2012).

The model was set up with a daily time step and 250 by $250 \mathrm{~m}$ grid cells. The calibration period was 1 September 2008 to 31 August 2009, while validation was from 1 September 2007 to 31 August 2008. The length of the calibration and validation was selected to optimize the model for snow conditions occurring in the period selected for sensitivity analysis (Sect. 2.4.1). The global WetSpa parameters were calibrated using the Shuffled Complex Evolution algorithm (Duan et al., 1993). The calibration was conducted with the R software (R Development Core Team, 2013) and package "hydromad". The model was optimized to maximize the Nash and Sutcliffe (1970) efficiency (NSE):

$$
\mathrm{NSE}=1-\frac{\sum_{x=1}^{\tau}\left(Q_{x}-\hat{Q}_{x}\right)^{2}}{\sum_{x=1}^{\tau}\left(Q_{x}-\bar{Q}\right)^{2}},
$$

where $Q_{x}$ and $\hat{Q}_{x}$ are observed and simulated discharges at time $x, \bar{Q}$ is the mean observed discharge and $\tau$ is the total number of time steps. Sensitivity of the WetSpa model to the global parameters is presented in Yang et al. (2012).

\subsection{Study area}

The study area is the Biebrza River catchment upstream from the discharge station at Burzyn. The total catchment area comprises $6845 \mathrm{~km}^{2}$ (Fig. 1). Biebrza is a lowland catchment consisting of moraine plateaus and post-glacial valleys with low slopes (average $1.03 \%$, Fig. 2) and an elevation ranging from $102 \mathrm{~m}$ a.s.l. at the catchment outlet to $298 \mathrm{~m}$ a.s.l. at the northern water divide. Land use is composed of agriculture $(54 \%)$, forests $(26 \%)$, wetlands and grasslands $(17 \%)$, water $(2 \%)$ and urban (1\%) (Fig. 3). The area is considered seminatural, especially because of its large area of well-preserved wetlands and forests and is therefore used as a reference area in wetlands research (Wassen et al., 2006). Several lakes in the northern part of the catchment are controlled by management schemes, which usually discharge into Biebrza trib- 


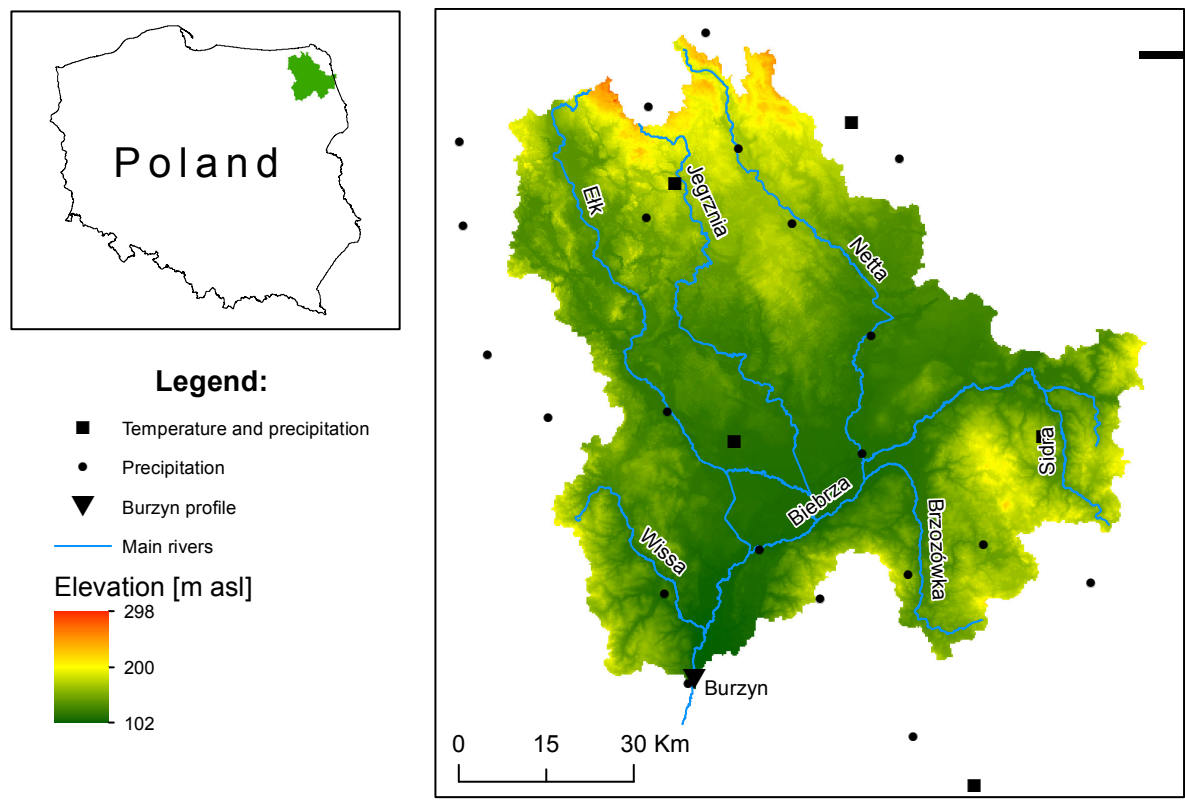

Figure 1. Topography of the study area and location of meteorological stations.

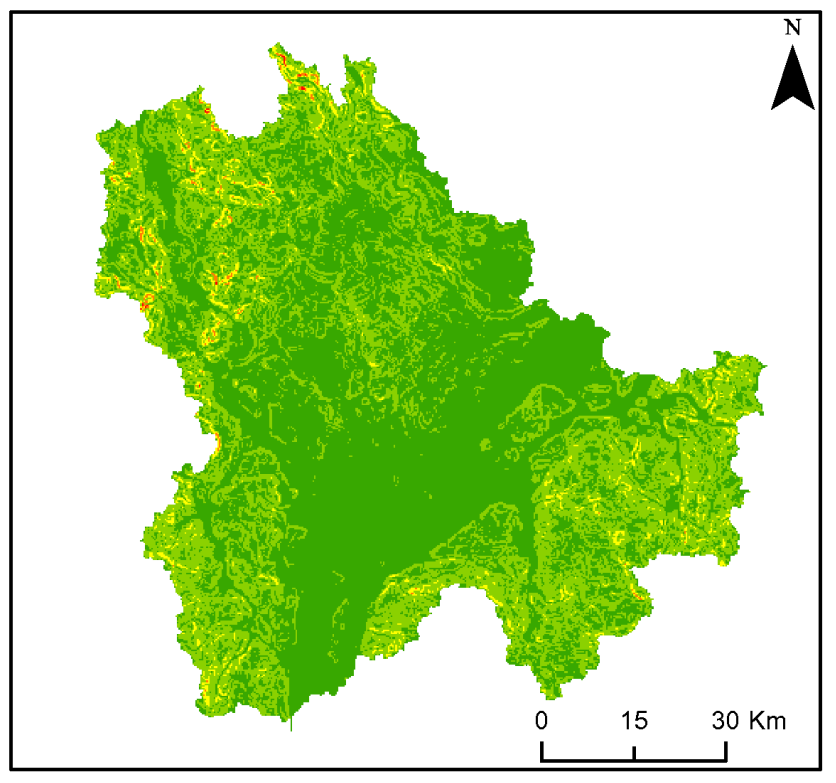

Slope [\%]

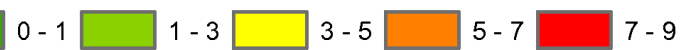

Figure 2. Slope map of the study area.

utaries after the accumulation period. Lakes in WetSpa are modelled by setting appropriate values of the hydraulic parameters in the model, e.g. by a high runoff coefficient and low friction. The simulation of water management schemes in the controlled lakes is, however, not implemented. Dominant soil textures in the study area are sand (34\%), loamy sand $(26 \%)$ and sandy loam (18\%), whereas minor parts are covered by sandy clay (4\%) and silt (2\%) and other soils cover less than $1 \%$ of the area. In the river valley, organic soils are frequent and cover in total $16 \%$ of the study area (Fig. 4). The dominating landscape features that certainly have influence on the functioning of the Biebrza hydrological system are the river valley and the large forest complex located in the north-eastern part of the catchment (Fig. 5).

The Biebrza River is characterized by a spring flood regime; the discharge of the spring flood is mostly related to the volume of snowmelt in the catchment (Stachý, 1987; Mioduszewski et al., 2004; Chormański and Batelaan, 2011). Based on the meteorological record from 25 stations and the flow record at the Burzyn profile (Fig. 1) managed by the Polish Institute of Meteorology and Water Management National Research Institute (IMGW), the study area can be characterized by the following figures. Mean yearly discharge (1951-2012) at Burzyn is $34.9 \mathrm{~m}^{3} \mathrm{~s}^{-1}$, while summer and winter averages are respectively 26.0 and $43.9 \mathrm{~m}^{3} \mathrm{~s}^{-1}$. Recorded extreme low and high discharges (1951-2012) are 4.33 and $517 \mathrm{~m}^{3} \mathrm{~s}^{-1}$ respectively. The climate in this area is transitional between continental and Atlantic with relatively cold winters and warm summers, effectively making this area the coldest region in lowland Poland. The mean air temperature (1979-2009) is $7.0^{\circ} \mathrm{C}$; in the winter half-year it is $0.3^{\circ} \mathrm{C}$ and in the summer half-year $13.7^{\circ} \mathrm{C}$. The mean monthly temperature (1979-2009) has a maximum in July $\left(17.6^{\circ} \mathrm{C}\right)$ and minimum in January $\left(-3.3^{\circ} \mathrm{C}\right)$. The yearly precipitation (1979-2009) is $587 \mathrm{~mm}(375 \mathrm{~mm}$ in the summer halfyear, $212 \mathrm{~mm}$ in the winter half-year). The yearly average number of days with temperature below $0^{\circ} \mathrm{C}$ (1979-2009) is 79 and with snow cover (1975-2012) is 93 (average snow depth is $12 \mathrm{~cm}$ ). Based on the meteorological maps (Stachý, 


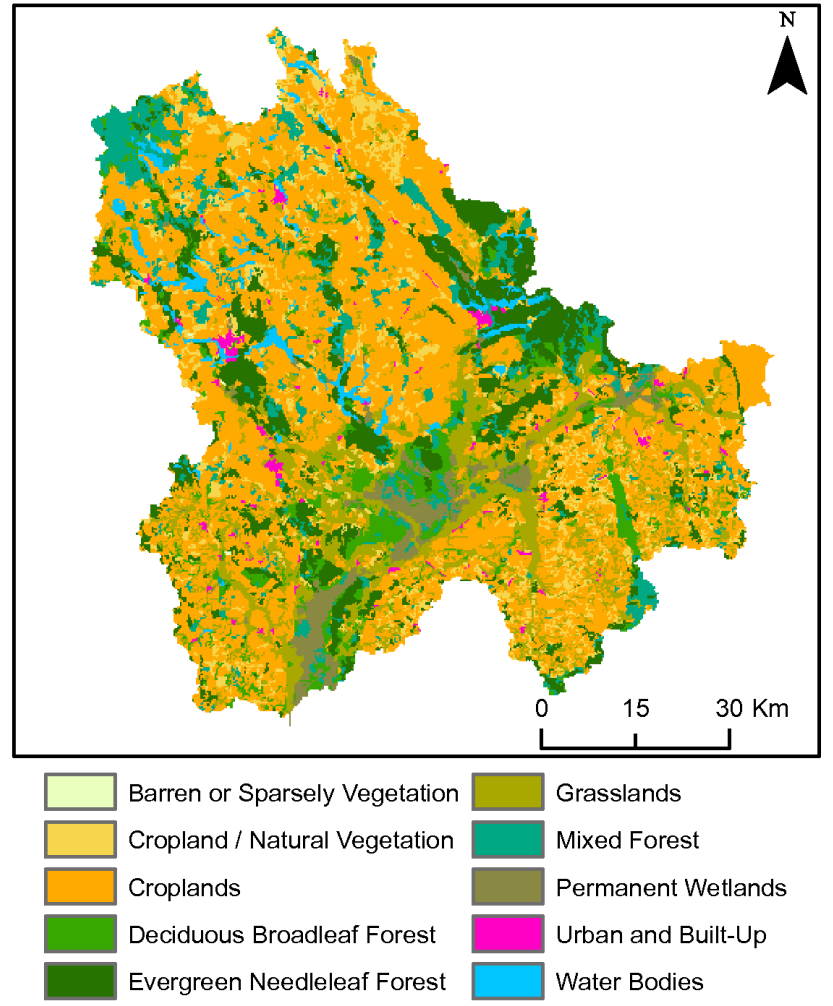

Figure 3. Land use in the study area. Land-use classes are the same as used in the WetSpa model, defined by International GeosphereBiosphere Programme classification system.

1987; Rojek, 2000), the mean yearly evaporation from free water surface $(1951-2000)$ is $550 \mathrm{~mm}, 465 \mathrm{~mm}$ in summer and $85 \mathrm{~mm}$ in winter (1951-1970).

\subsection{Data}

Hydrometeorological data (precipitation, air temperature and discharge) were obtained from IMGW. Daily precipitation was obtained for 25 rain gauge stations, whereas air temperature was available for 5 stations (Fig. 1). Temperature was recorded as minimum and maximum daily temperature; an average from these values was calculated to obtain the mean daily temperature for each station. Daily discharge was obtained for Burzyn. Potential evapotranspiration was estimated based on mean monthly evaporation from free water surface (Stachý, 1987) and uniformly disaggregated into daily values.

Daily SCF was obtained from MODIS/TERRA snow product MOD10A1 (Hall et al., 2006, datasets used: IX 2007 to $X$ 2009) with a $500 \mathrm{~m}$ resolution. The SCF values in MOD10A1 are calculated based on the Normalized Difference Snow Index (NDSI):

$\mathrm{NDSI}=\frac{r_{\mathrm{vis}}-r_{\mathrm{ir}}}{r_{\mathrm{vis}}+r_{\mathrm{ir}}}$,

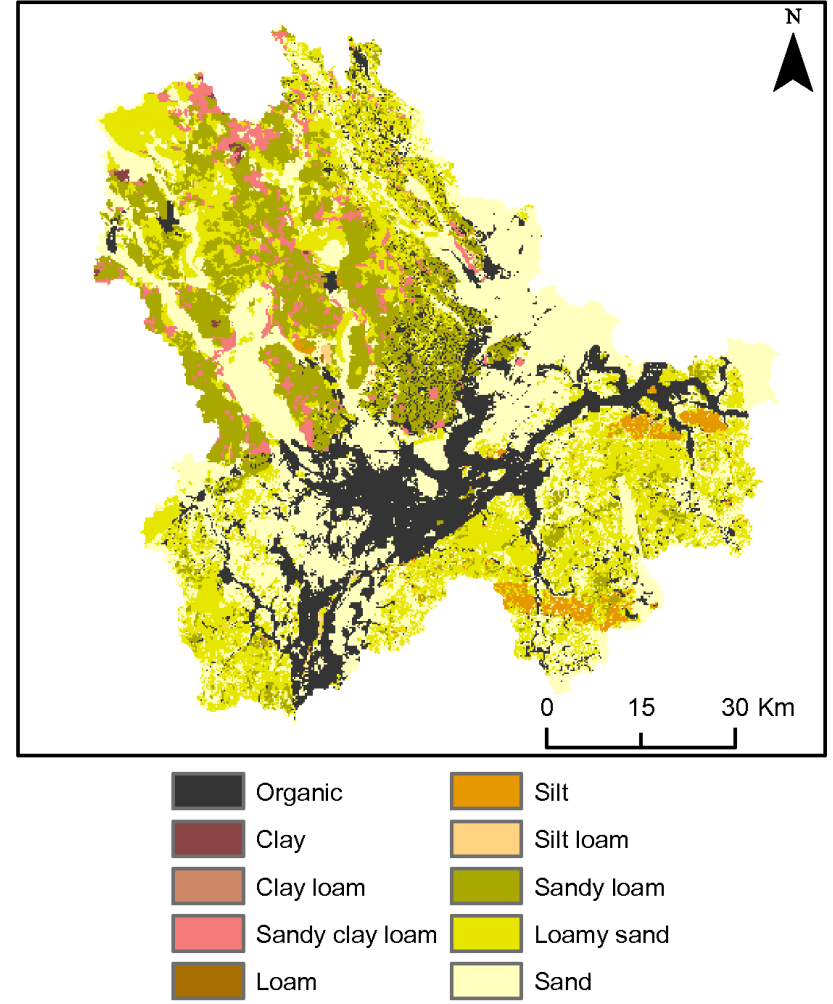

Figure 4. Soil texture map of the study area. Soil textures are the same as used in the WetSpa model, defined by the US Department of Agriculture.

where $r_{\text {vis }}$ and $r_{\text {ir }}$ are the reflectance visible and in nearinfrared bands, which for the MODIS sensor are respectively bands $4(545-565 \mathrm{~nm})$ and $6(1628-1652 \mathrm{~nm})$. In general, NDSI gives higher values when a larger part of a pixel is covered by snow. However, it may be affected by noise from many sources and has to be corrected for bias in forest areas (Klein et al., 1998). The MOD10A1 SCF input data were aggregated into $5244 \mathrm{~km}$ by $4 \mathrm{~km}$ snow zones, while zones close to the catchment boundary are fractions of a $4 \mathrm{~km}$ square. The purpose of the aggregation was to decrease computation time of the sensitivity analysis and reduce noise in the MOD10A1 data while keeping enough variability to obtain meaningful spatial results. In order to remove missing data related to cloud cover occurrence the SCF in snow zones was linearly interpolated over time. Finally, SCF was set to 0 in months when there was no snow recorded in lowland Poland, i.e. from May to September. The aggregated MOD10A1 SCF data in snow zones were used to calibrate the WetSpa model. For the spatial sensitivity analysis, however, the daily time series of catchment averages of MOD10A1 SCFs were used; i.e. the spatial pattern of SCF in snow zones was obtained by perturbing the catchment averages by random factors (Sect. 2.4.1).

Spatial data (elevation, land use and soil) used to calculate distributed model parameters were obtained from vari- 
able GIS sources. The elevation map (Fig. 1) was compiled from three sources: the digital elevation model of Poland on a scale of 1:26,000, digitized contours from the topographical map of Poland on a scale of $1: 25000$ and from field surveys in the Biebrza valley (Maciorowski et al., 2014). The land-use map (Fig. 3) was obtained from the Corine Land Cover 2006 project (Commission of the European Communities, 2013). In the catchment area outside the Polish border $\left(56 \mathrm{~km}^{2}\right)$, agricultural land-use was assigned. The soil map (Fig. 4) was obtained from the soil map of Poland with a scale of 1:50000 for agricultural areas and 1:500000 in forests and cities. Outside the Polish border the most frequent in the neighbourhood, sandy soil, was assigned. All the spatial data were interpolated to $250 \mathrm{~m}$ grid cells using the nearest-neighbourhood (soil, land use) and the bilinear (elevation) algorithms.

\subsection{Sensitivity analysis}

\subsubsection{Spatial sensitivity analysis with Latin-Hypercube One-factor-At-a-Time algorithm}

Usually a sensitivity analysis is performed for global parameters of a model (i.e. a set of parameters valid for the whole model area). The sensitivity analysis presented in this paper, however, follows a spatial approach, i.e. parameters $(e)$ are evaluated in different zones of the model area. In this case study the parameter $e_{i}$ represents a fraction of the daily averaged MOD10A1 SCF assigned into the zone $i$. Since $e_{i}$ is randomly sampled the MOD10A1 data constrain only the temporal dynamics of SCF. Hence, results of the sensitivity analysis are interpretable in terms of SCF as input data in general rather than in terms of MOD10A1 in particular.

LH-OAT (van Griensven et al., 2006) is an effective global sensitivity analysis method, similar to the Morris screening (Morris, 1991). The LH-OAT method is frequently used by SWAT users for ranking the parameters according to their influence on the model output (Nossent and Bauwens, 2012). LH-OAT combines two different techniques. First, it selects $n$ latin-hypercube (McKay et al., 1979) samples. Next, the LH points are used as starting points of $p$ one-factor-at-atime perturbations, where $p$ is equal to the number of model parameters. A higher number of LH samples $(n)$ will lead to a better convergence; a value of at least $n=100$ is necessary to achieve convergence (Nossent, 2012; Nossent et al., 2013). The method requires in total $p(n+1)$ model evaluations to calculate the sensitivity analysis results. The sensitivity measure (final effect) for each $i$ th parameter is calculated by averaging partial effects for this parameter $\left(s_{i, j}\right)$ from all LH samples (van Griensven et al., 2006):

$$
s_{i, j}=\left|\frac{100\left(\frac{F\left(e_{1}, \ldots, e_{i}\left(1+f_{i}\right), \ldots, e_{p}\right)-F\left(e_{1}, \ldots, e_{i}, \ldots, e_{p}\right)}{\left[F\left(e_{1}, \ldots, e_{i}\left(1+f_{i}\right), \ldots, e_{p}\right)+F\left(e_{1}, \ldots, e_{i}, \ldots, e_{p}\right)\right] / 2}\right)}{f_{i}}\right|,
$$

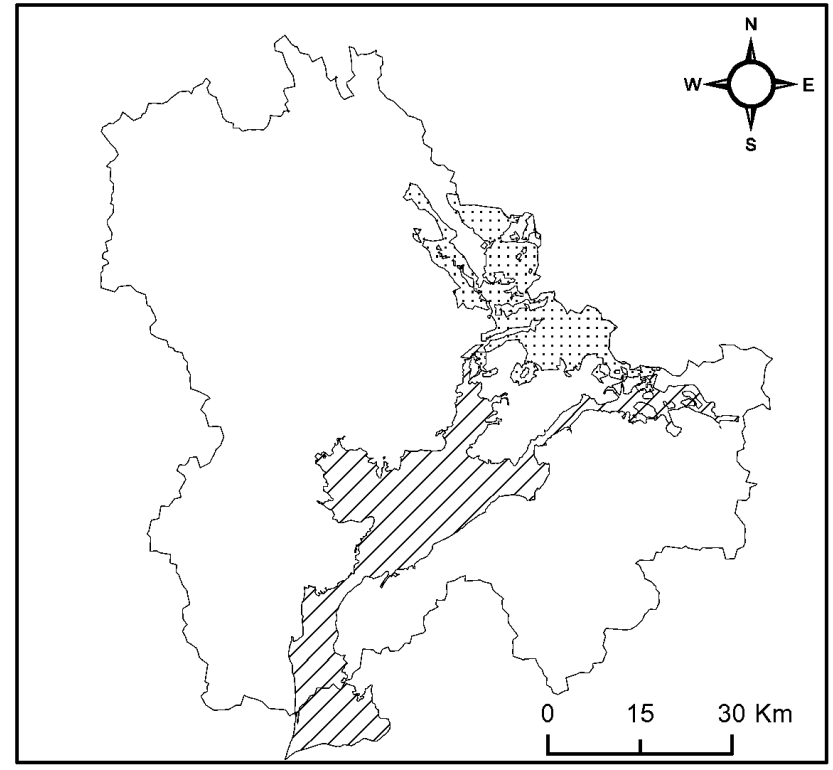

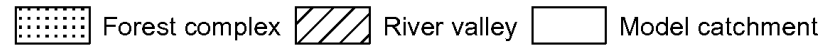

Figure 5. Major landscape features of the Biebrza River catchment. The Biebrza River valley runs NE-SW through the catchment with at the upstream part of the valley a large forest complex. Catchment area outside the river valley is upland/plateau with mineral soils.

$s_{i}=\frac{\sum_{j=1}^{n} s_{i j}}{n}$,

where $F($.$) is a response or objective function of a model$ run with a set of $e_{1}$ to $e_{p}$ parameters, $e_{i}$ is the current parameter and $j$ is the current LH sample ranging between 1 and $n$; $f_{i}$ is the fraction by which $e_{i}$ was changed during the OAT perturbation, the sign of which is random at each loop as the value can increase or decrease. Since the small snow zones at the catchment border would give relatively smaller sensitivity than similarly parametrized zones of bigger area, the $s_{i}$ measure has to be normalized for non-equal area $\left(a_{i}\right)$ of snow zones. Thus, the normalized sensitivity $\left(s_{i}^{\star}\right)$ is defined as

$\stackrel{\star}{s_{i}}=\frac{s_{i}}{a_{i}}$.

$\Sigma_{i}^{\star}$ should be interpreted as a response measure of the changes in SCF in the snow zones to the value of $F($.$) ; a higher sensi-$ tivity stands for a stronger response and means that the model output is more vulnerable to uncertainty in a particular snow zone. This study design allows to obtain SCF sensitivity in each snow zone of the model. Insights into model sensitivity while simulating different processes can be achieved by using various response functions as $F$ (.) (Sect. 2.4.2). The 


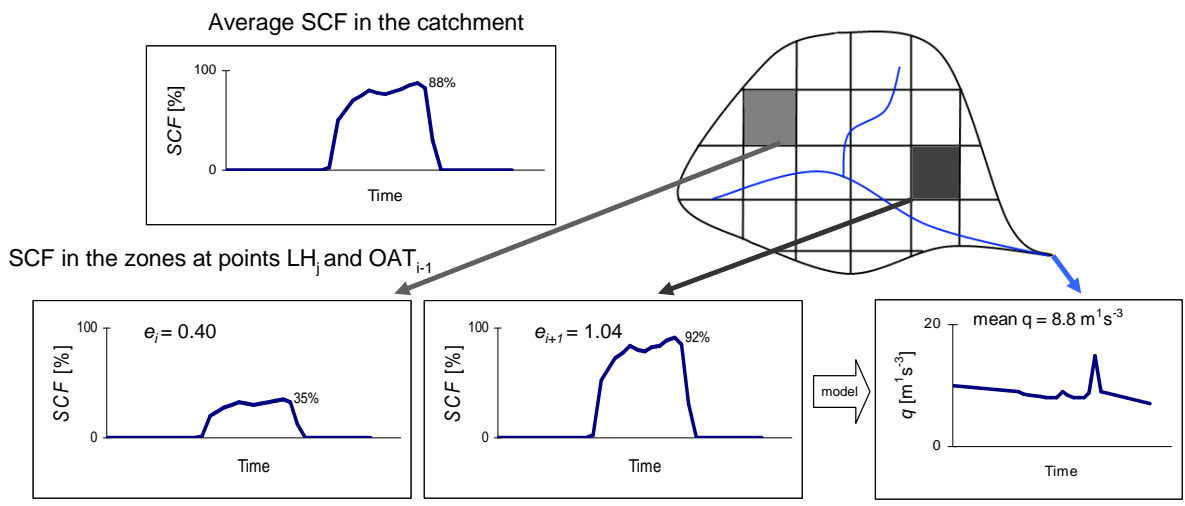

SCF in the zones at points $\mathrm{LH}_{\mathrm{i}}$ and $\mathrm{OAT}$
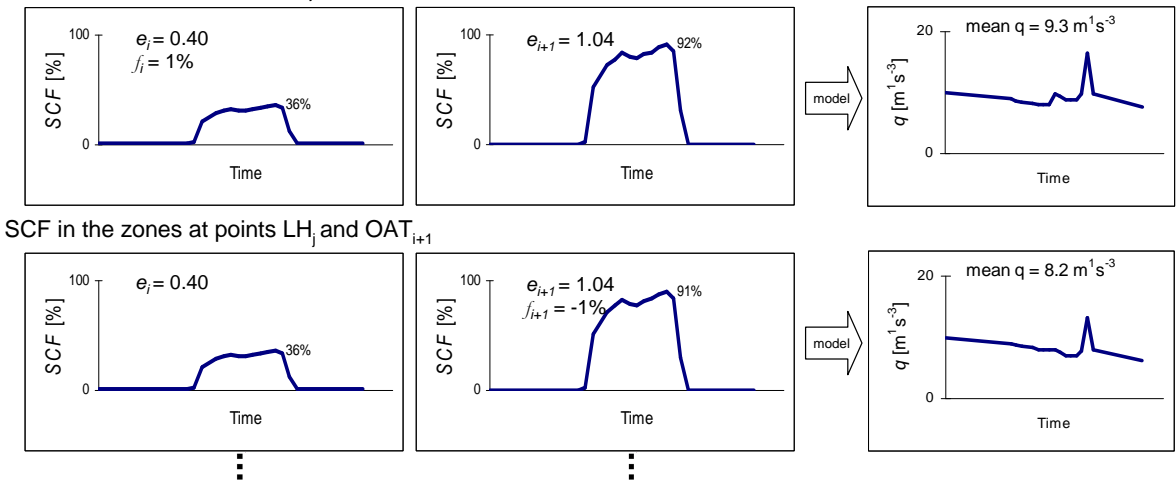

SCF in the zones at points $\mathrm{LH}_{\mathrm{j}+1}$ and $\mathrm{OAT}_{\mathrm{i}-1}$
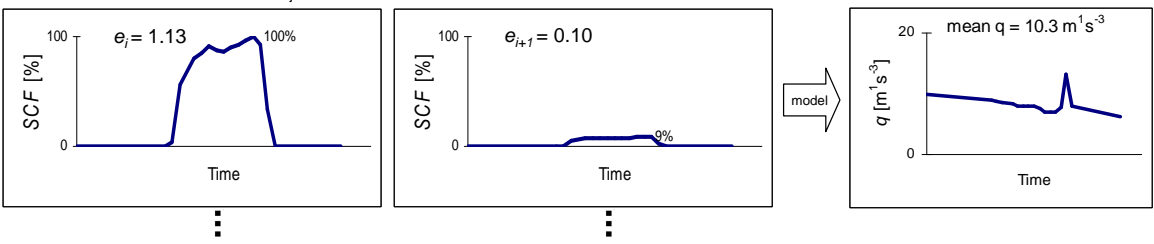

Figure 6. Graph illustrating the spatial LH-OAT SCF sampling for calculating the sensitivity analysis. The top row presents a spatially averaged observed SCF for an example catchment (top left panel) and the example catchment with highlighted snow zones $i$ and $i+1$ (top right panel). The next rows present SCF in the zones $i$ (panels in the left column) and $i+1$ (panels in the central column) in the advancing LH-OAT loops starting from the loop $[i-1, j]$ and the discharge simulated during these loops (panels in the right column). Symbols are the same as in Eq. (4): $e_{i}$ and $e_{i+1}$ represent a fraction of the SCF in the snow zones $i$ and $i+1, f$ is the fraction by which $e$ was changed during the OAT perturbation, $j$ and $j+1$ represent the subsequent LH samples, $q$ is the discharge simulated at the catchment outlet.

example of LH-OAT loops for spatial sensitivity analysis described above is presented in Fig. 6.

The experimental set-up for the spatial sensitivity was as follows. The values of the global parameters of the WetSpa model were the same as those obtained from the model calibration. To be able to achieve convergence, a relatively large number of LH samples was selected $(n=100)$. Together with the sample of $e_{i}$ parameters representing 524 $4 \mathrm{~km} \times 4 \mathrm{~km}$ snow zones $(p=524)$, this results in a total number of model evaluations of 52500. The LH samples are taken from a uniform distribution ranging from 0 to 1.14 , resulting in a range of 0 to 1 for the SCF in a snow zone (maximum daily mean SCF in the catchment was $88 \%$; thus $\left.\frac{1}{0.88}=1.14\right)$. The perturbation $f_{i}$ was set to $1 \%$ in order to avoid the OAT samples exceeding the average distance be- tween the LH samples. The sensitivity analysis was run for 2 full hydrological years from 1 November 2007 to 31 October 2009 , preceded by a warm-up period of 2 months.

\subsubsection{Response functions}

In order to investigate the relationship between parameters and different model processes, the sensitivity analysis was performed for a set of response functions $F($.). A response function quantifies a model behaviour but, unlike an objective function, a response function does not use observation (e.g. observed discharge). Table 1 lists the 15 response functions which were used in the sensitivity analysis. This selection of response functions allows us to interpret the results in light of different components of the discharge as simulated by a number of model processes related to them. Moreover, 
Table 1. Descriptions and abbreviations of the 15 response functions (RF) which were used in the sensitivity analysis.

\begin{tabular}{lccc}
\hline Description & \multicolumn{3}{c}{ RF abbreviation } \\
& Yearly & Winter & Summer \\
\hline Mean simulated discharge & $\bar{q}$ & $\bar{q}_{\mathrm{w}}$ & $\bar{q}_{\mathrm{s}}$ \\
Mean simulated discharge from surface runoff & $\overline{q s}$ & $\overline{q s}_{\mathrm{w}}$ & $\overline{q s}_{\mathrm{s}}$ \\
Mean simulated discharge from interflow & $\frac{q i}{q g}$ & $\overline{q i}_{\mathrm{w}}$ & $\bar{q}_{\mathrm{s}}$ \\
Mean simulated discharge from groundwater & $\overline{q g}$ & $\overline{\mathrm{q}}$ \\
Mean of the highest 10\% simulated discharges & $\bar{q}_{\mathrm{h}}$ & - & - \\
Mean of the lowest 10\% simulated discharges & $\bar{q}_{\text {low }}$ & - & - \\
Mean simulated snowmelt & $\bar{v}_{\mathrm{sm}}$ & - & - \\
\hline
\end{tabular}

the division into winter and summer half-years gives more insight into the seasonal variability of the simulated results. The winter half-year response functions reflect processes occurring during snow accumulation and spring snowmelt when the highest flows occur. However, the summer halfyear response functions reflect processes occurring during the summer low flow period. Winter half-year response function were calculated for November until April, summer halfyear response function for May until October. The $\bar{q}_{\text {high }}$ and $\bar{q}_{\text {low }}$ reflect processes related to the highest and lowest flows. The $\bar{v}_{\text {sm }}$ is calculated as the mean daily value of snowmelt $(\mathrm{mm})$ and reflects processes related to snowmelt generation without routing.

\subsubsection{Output data analysis}

The spatial approach followed in this study gives a large output data set, i.e. sensitivity maps based on different response functions. Each sensitivity map was analyzed in light of 15 WetSpa parameter maps presented in Table 2. The Thiessen polygons for potential evapotranspiration were omitted, as there was only one polygon for the whole catchment.

In order to prepare the data set for statistical analysis, each of the 15 parameter maps was spatially aggregated to fit the spatial extent of the sensitivity analysis results $\left(s_{i}^{\star}\right)$ of the snow zones by calculating the mean (for continuous data) or the majority (for discrete data) of a parameter value in a snow zone. Based on this data set the coefficient of determination $\left(\rho^{2}\right)$ was calculated for each pair of $\hat{s}_{i}$ and the aggregated parameter values. The $\rho^{2}$ describes the strength of the linear association between the variables by indicating the fraction of one variable's variance explained by the second variable. Since in literature the thresholds of $\rho^{2}$ for quantifying the strength of the linear association are vague, in this paper a $\rho^{2} \geqslant 0.40$ is used to represent a moderate association.

\section{Results}

\subsection{Model calibration and performance}

The calibrated model shows high efficiencies: $\mathrm{NSE}=0.86$ for the calibration period, NSE $=0.73$ for the validation period and NSE $=0.79$ for the whole period. The snowrelated global WetSpa parameters were estimated during the calibration as: $k_{\text {snow }}=5.03 \mathrm{~mm}^{\circ} \mathrm{C}^{-1}$ day $^{-1}, k_{\text {rain }}=$ $0.02 \mathrm{~mm} \mathrm{~mm}^{-1}{ }^{\circ} \mathrm{C}^{-1} \mathrm{day}^{-1}$. The comparison of observed and simulated discharge is presented in Fig. 7. Of the simulated discharge at the catchment outlet, $90 \%$ has a groundwater origin, while surface runoff $(5.3 \%)$ and interflow $(4.7 \%)$ contribute mostly to the highest peaks (Fig. 7).

\subsection{Spatial sensitivity analysis}

The maps presenting global model output sensitivities $\stackrel{s}{s}_{i}$ to variations of spatial SCF are presented in Fig. 8. The use of different response function results in different patterns of spatial sensitivity, although some similarities can be distinguished as well. The minimum, maximum and mean values are indicated on each map (Fig. 8). When the minimum is equal to 0 , the model is completely insensitive in at least one snow zone for this response function. The values presented in the first four rows can be compared within a row; however, comparison between the rows is more difficult as in different rows the response functions concern discharge components of different magnitude. Note that the grey scale is different for all maps in the lowest row. This is because, unlike in the upper rows, the $\stackrel{s}{s}_{i}$ calculated from these response functions are not intended to be compared within this row as they concern different processes.

The analysis of $\rho^{2}$ values (Table 3 ) explains the spatial relations between SCF sensitivity with different response function and the spatial parameters. Most of the pairs in Table 3 have low $\rho^{2}$, suggesting that a parameter was not relevant for sensitivity with this response function. However, for most of the response functions at least one $\rho^{2} \geqslant 0.40$ was found, indicating that the SCF sensitivity with these response functions can be partially explained by the values of the parameter maps. The values of $\rho^{2}$ show influential and unimportant spatial parameters for the SCF sensitivity, i.e. for the snowrelated processes. Detailed analysis of Fig. 8 and Table 3 is provided in the subsequent subsections. 
Table 2. WetSpa parameter maps used to analyze the sensitivity analysis results: the generic input maps used to derive the parameters maps are marked with + when used and - when not used.

\begin{tabular}{llccc}
\hline Parameter & Abbreviation & \multicolumn{3}{c}{ Generic input map } \\
& & Soil & Land use & Elevation \\
\hline Slope & slp & - & - & + \\
Hydraulic conductivity & $h \_c o n$ & + & - & - \\
Soil field capacity & $f \_c a p$ & + & - & - \\
Maximal interception & $i \_$max & - & + & - \\
Minimal interception & $i \_$min & - & + & - \\
Pore size distribution index & $p \_$ind & + & - & - \\
Soil porosity & por & + & - & - \\
Residual soil moisture content & res & + & - & - \\
Root depth & $r \_d$ & - & + & - \\
Wilting point & $w \_p$ & + & - & - \\
Runoff coefficient & $r \_c$ & + & + & + \\
Depression storage & dep & + & + & + \\
Initial soil moisture content & $i \_s m$ & + & - & + \\
Mean temperature in Thiessen polygons & $T$ & & from the stations \\
Precipitation sum in Thiessen polygons & $P$ & & from the stations \\
\hline
\end{tabular}
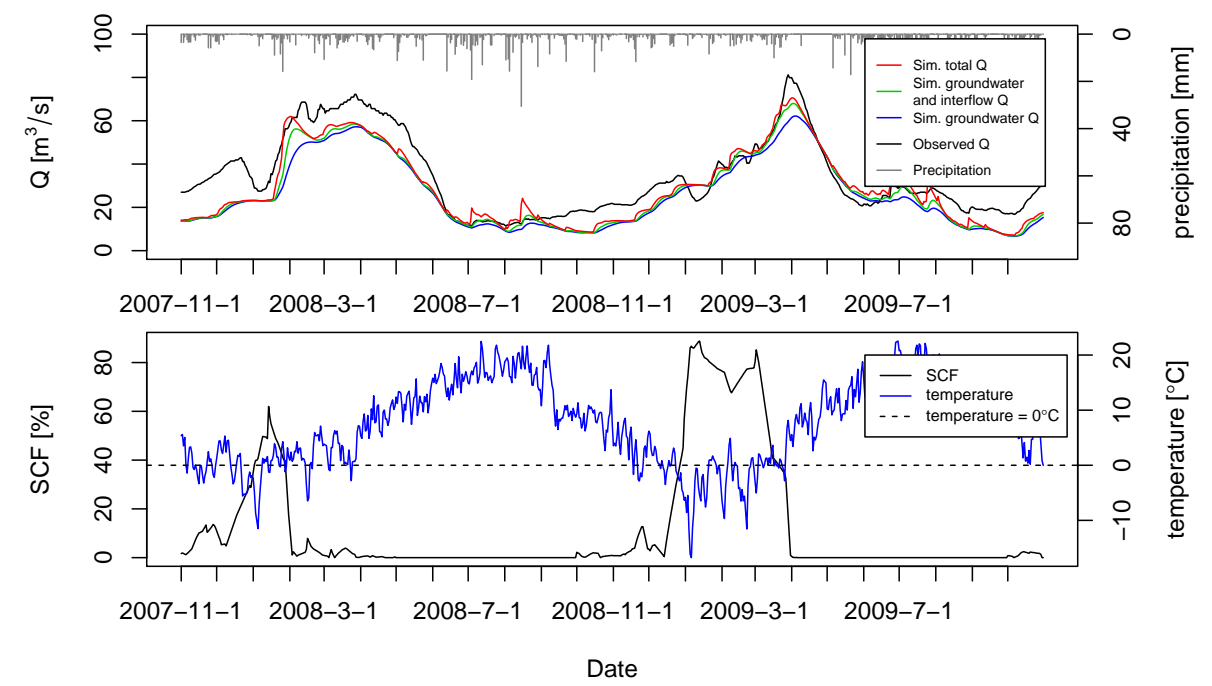

Figure 7. Observed and simulated daily discharge from the calibrated WetSpa for the period in which the sensitivity analysis was conducted (upper panel). Also presented is WetSpa simulated groundwater and interflow discharge as well as only groundwater discharge. Catchment average daily temperature and SCF in the same period is presented in the lower panel. The ticks on the time axis indicate the 1st day of a month.

\subsubsection{General relations of the spatial sensitivity analysis results with parameters maps}

The last column of Table 3 shows the frequency of the parameters with moderately strong coefficient of determination under different response functions. The most frequently occurring parameter with a coefficient of determination above the threshold (0.40) is slope. The second-most frequent is the group of soil-texture-related parameters: wilting point, hydraulic conductivity, porosity, residual soil moisture and field capacity. The lowest frequency is observed for maximal and minimal interception, initial soil moisture, root depth as well as parameters responsible for generating surface runoff - runoff coefficient and depression storage.

The scatter plots of the slope versus different response functions (Fig. 9) show that this parameter strongly correlates with the spatial sensitivity quantified with $\bar{q}, \overline{q i}$ and $\overline{q g}$ and their winter/summer half-years equivalents. However, when looking closer at the plots for these response functions, the lower values of the slope $(0.0-0.5 \%)$ give steeper relations with less scatter than higher slope values. 


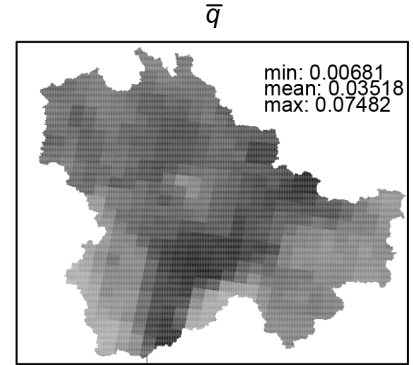

$\overline{q s}$

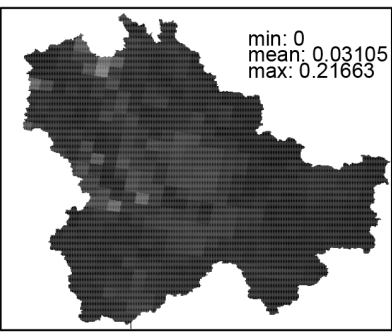

$\overline{q i}$

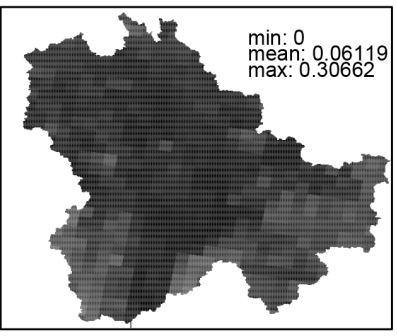

$\overline{q g}$

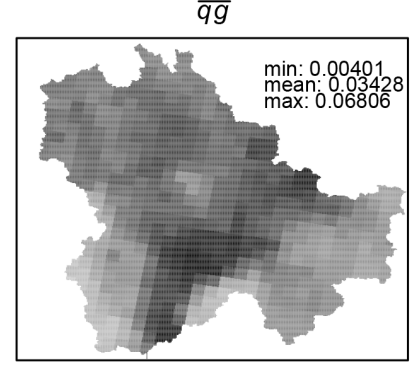

$\bar{q}_{\text {high }}$

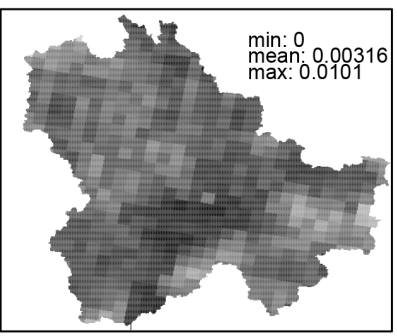

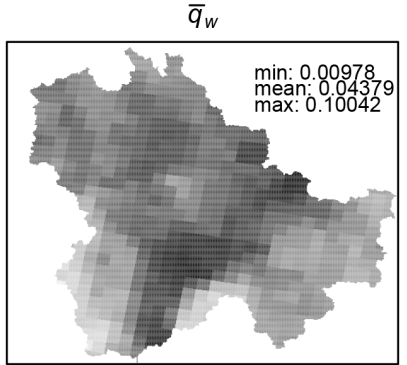

$\overline{q s}_{w}$

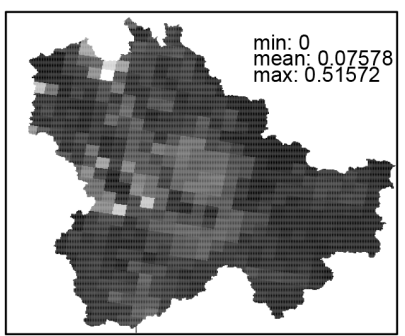

$\overline{q i}_{w}$

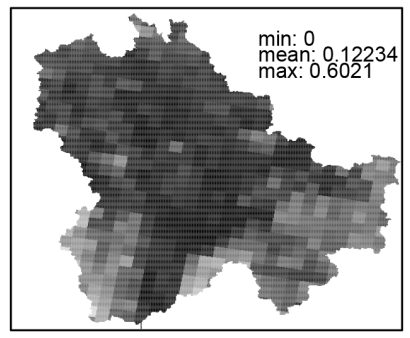

$\overline{q g}_{w}$

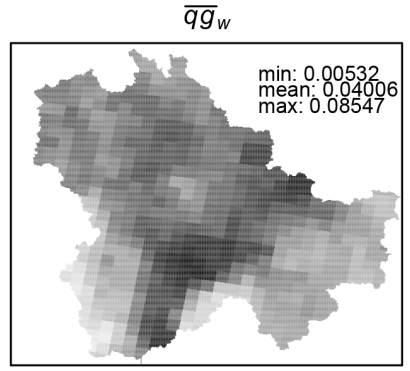

$\bar{q}_{\text {low }}$

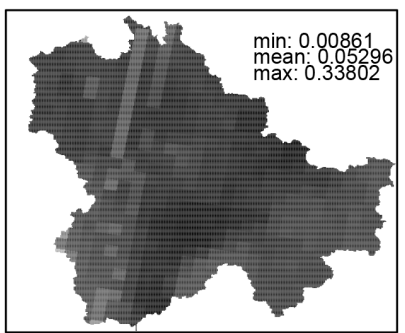

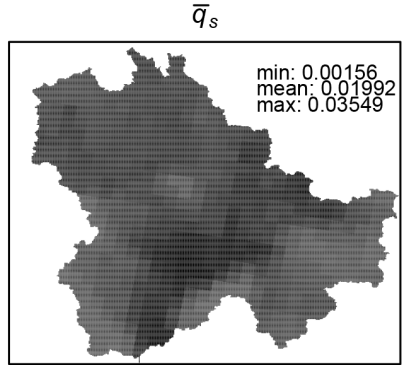

$\overline{q s}_{s}$

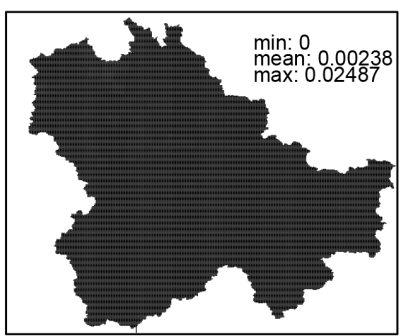

$\overline{q i_{s}}$

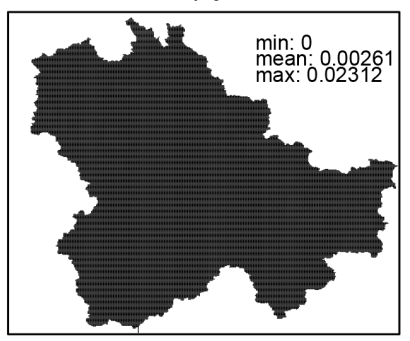

$\overline{q g}_{s}$

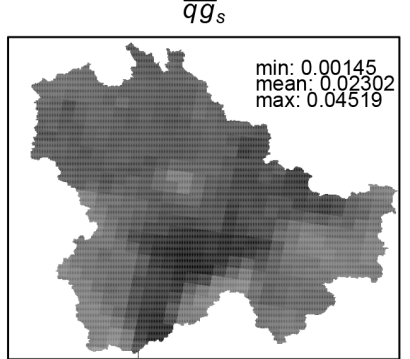

$\bar{v}_{s m}$

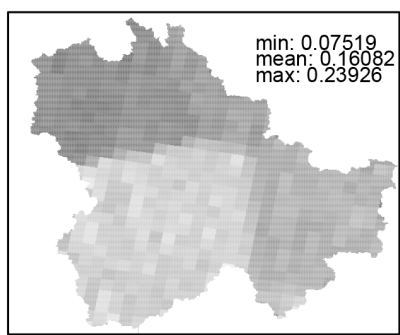

Figure 8. The SCF sensitivity maps showing $s_{i}^{\star}$ in snow zones of the WetSpa model for Biebrza River catchment for different response functions. The grey scale represents linearly stretched $s_{i}^{\star}$ values between minimum (black) and maximum (white); for the top four rows the grey scale is selected to match the data range of all maps in each row; in the lowest row each map has individual grey scale between the minimum and maximum values indicated on the plots (see Sect. 3.2 for details). Explanation of the response functions is presented in Table 1. 
Table 3. $\rho^{2}$ values calculated for the WetSpa distributed parameters (rows) and the SCF sensitivity maps under different response functions (columns). $\rho^{2} \geqslant 0.40$ are bold; the frequency that this condition is true is summarized $\left(\sum\right)$ in the last row and column. Explanation of the response functions and parameters is presented in Tables 1 and 2.

\begin{tabular}{|c|c|c|c|c|c|c|c|c|c|c|c|c|c|c|c|c|}
\hline & $\bar{q}$ & $\bar{q}_{\mathrm{w}}$ & $\bar{q}_{\mathrm{s}}$ & $\overline{q s}$ & $\overline{q s}_{\mathrm{W}}$ & $\overline{q s_{\mathrm{S}}}$ & $\overline{q i}$ & $\overline{q i}_{\mathrm{w}}$ & $\overline{q i_{\mathrm{S}}}$ & $\overline{q g}$ & $\overline{q g}_{\mathrm{W}}$ & $\overline{q g}_{\mathrm{s}}$ & $\bar{q}_{\text {high }}$ & $\bar{q}_{\text {low }}$ & $\bar{v}_{\mathrm{sm}}$ & $\sum$ \\
\hline slp & 0.58 & 0.58 & 0.48 & 0.00 & 0.00 & 0.02 & 0.45 & $\begin{array}{l}0.44 \\
\end{array}$ & 0.23 & 0.56 & 0.56 & 0.45 & 0.36 & 0.12 & 0.09 & 8 \\
\hline$h_{-}$con & 0.00 & 0.00 & 0.00 & 0.40 & 0.40 & 0.28 & 0.16 & 0.15 & 0.11 & 0.00 & 0.00 & 0.00 & 0.01 & 0.00 & 0.00 & 2 \\
\hline$f_{\text {_cap }}$ & 0.25 & 0.20 & 0.41 & 0.15 & 0.15 & 0.02 & 0.24 & 0.24 & 0.14 & 0.27 & 0.23 & 0.40 & 0.15 & 0.18 & 0.12 & 2 \\
\hline i_max & 0.00 & 0.01 & 0.00 & 0.03 & 0.03 & 0.03 & 0.00 & 0.00 & 0.07 & 0.00 & 0.00 & 0.00 & 0.00 & 0.00 & 0.01 & 0 \\
\hline$i \_$min & 0.09 & 0.07 & 0.16 & 0.03 & 0.03 & 0.01 & 0.03 & 0.04 & 0.02 & 0.10 & 0.08 & 0.16 & 0.05 & 0.02 & 0.01 & 0 \\
\hline$p \_$ind & 0.09 & 0.07 & 0.20 & 0.21 & 0.20 & 0.42 & 0.00 & 0.00 & 0.01 & 0.08 & 0.06 & 0.18 & 0.06 & 0.18 & 0.20 & 1 \\
\hline por & 0.25 & 0.20 & 0.44 & 0.03 & 0.04 & 0.00 & 0.16 & 0.16 & 0.10 & 0.26 & 0.22 & 0.42 & 0.15 & 0.22 & 0.17 & 2 \\
\hline res & 0.25 & 0.20 & 0.42 & 0.10 & 0.11 & 0.01 & 0.20 & 0.20 & 0.12 & 0.27 & 0.23 & 0.41 & 0.15 & 0.19 & 0.13 & 2 \\
\hline$r \_\mathrm{d}$ & 0.00 & 0.01 & 0.00 & 0.12 & 0.12 & 0.08 & 0.00 & 0.00 & 0.04 & 0.00 & 0.00 & 0.01 & 0.00 & 0.00 & 0.01 & 0 \\
\hline$w \_p$ & 0.25 & 0.21 & 0.42 & 0.14 & 0.14 & 0.02 & 0.23 & 0.23 & 0.13 & 0.27 & 0.23 & 0.41 & 0.15 & 0.18 & 0.12 & 2 \\
\hline$r_{-}^{-1} \mathrm{c}$ & 0.03 & 0.02 & 0.11 & 0.30 & 0.30 & 0.12 & 0.11 & 0.10 & 0.04 & 0.05 & 0.03 & 0.12 & 0.02 & 0.08 & 0.06 & 0 \\
\hline dep & 0.26 & 0.26 & 0.24 & 0.11 & 0.11 & 0.15 & 0.05 & 0.05 & 0.06 & 0.24 & 0.24 & 0.22 & 0.14 & 0.06 & 0.03 & 0 \\
\hline$i_{-}$sm & 0.07 & 0.06 & 0.10 & 0.00 & 0.00 & 0.00 & 0.07 & 0.07 & 0.00 & 0.07 & 0.06 & 0.10 & 0.05 & 0.04 & 0.00 & 0 \\
\hline$T$ & 0.05 & 0.05 & 0.02 & 0.03 & 0.03 & 0.16 & 0.08 & 0.09 & 0.00 & 0.04 & 0.05 & 0.02 & 0.01 & 0.00 & 0.42 & 1 \\
\hline$P$ & 0.02 & 0.03 & 0.00 & 0.00 & 0.00 & 0.02 & 0.01 & 0.01 & 0.06 & 0.02 & 0.03 & 0.00 & 0.04 & 0.08 & 0.19 & 0 \\
\hline$\sum$ & 1 & 1 & 5 & 1 & 1 & 1 & 1 & 1 & 0 & 1 & 1 & 5 & 0 & 0 & 1 & \\
\hline
\end{tabular}

\subsubsection{Discharge source response functions}

Using $\bar{q}$ and $\bar{q}_{\mathrm{w}}$ as response functions resulted in a clear pattern differentiating the upland from the valley (cf. Figs. 8 and 5), showing that SCF zones occurring in the flat, organicsoil-dominated valley is much less sensitive than in the mineral upland. High sensitivity is obtained in snow zones with steeper slopes (cf. Figs. 8 and 2), which is confirmed by high $\rho^{2}$ (Table 3). Several WetSpa parameters (mostly soiltexture-dependent: depression storage, wilting point, field capacity, porosity, residual soil moisture content) have high $\rho^{2}$ with $\bar{q}$ and $\bar{q}_{\mathrm{w}}$ response functions (Table 3 ).

Some differences between $\bar{q}$ and $\bar{q}_{\mathrm{s}}$ are visible when analysing $\rho^{2}$ (Table 3 ). The SCF sensitivity for $\bar{q}_{\mathrm{s}}$ has higher $\rho^{2}$ for parameters that are related to groundwater flow, like porosity, residual soil moisture content, field capacity and pore size distribution index.

When comparing $\bar{q}, \bar{q}_{\mathrm{w}}$ and $\bar{q}_{\mathrm{s}}$ to $\overline{q g}, \overline{q g}_{\mathrm{w}}$ and $\overline{q g}_{\mathrm{s}}$ with respect to spatial patterns (Fig. 8) and $\rho^{2}$ (Table 3), the figures are very similar. The group of parameters responsible for groundwater processes (porosity, residual soil moisture content, field capacity and pore size distribution index) have higher $\rho^{2}$ with the groundwater response functions $\overline{q g}$ and $\overline{q g}_{\mathrm{w}}$ than with $\bar{q}$ and $\bar{q}_{\mathrm{w}}$.

The SCF sensitivity for $\overline{q s}$ and $\overline{q s}_{\mathrm{W}}$ differentiates the river valley and the north-western upland catchment from the south-eastern upland (cf. Figs. 8 and 5). The maps of SCF sensitivity for $\overline{q s}$ and $\overline{q s}_{\mathrm{w}}$ are the only ones that show clearly a relatively higher sensitivity in the river valley than in most of the upland.

The SCF sensitivity for the interflow response function differs from the groundwater and surface water response function results. The spatial pattern of SCF sensitivity for $\overline{q i}$ and $\overline{q i}_{\mathrm{w}}$ seems opposite to the pattern of $\overline{q s}$ and $\overline{q s}_{\mathrm{w}}$.

\subsubsection{Extreme discharges response functions}

The SCF sensitivity for $\bar{q}_{\text {high }}$ and $\bar{q}_{\text {low }}$ presents a spatial pattern that can not be visually related to land-use, soil or slope maps (Fig. 8). These response functions do not correlate with any of the WetSpa spatial parameters (Table 3). The spatial pattern of $\bar{q}_{\text {high }}$ shows high values both in the upland and in the valley; however it also has some zones of low sensitivity in the central part of valley. Low but noticeable $\rho^{2}$ is found only with the slope. The spatial pattern of $\bar{q}_{\text {low }}$ is quite uniform, with some higher values in the western uplands and lower values in the central part of the valley and in flat regions in the northern upland (cf. Figs. 5 and 8).

\subsubsection{Mean snowmelt response function}

The pattern of $\bar{v}_{\text {sm }}$ shows random values with different means in different Thiessen polygons for temperature stations used in the model (Fig. 8). This pattern is confirmed by high $\rho^{2}$ between $v_{\mathrm{sm}}$ and temperature, with no other parameters having noticeable $\rho^{2}$ (Table 3 ).

\section{Discussion}

\subsection{Model calibration and performance}

The groundwater-dominated discharge composition obtained with the calibrated model is in conceptual agreement with Pajnowska et al. (1984). The model performed well during snowmelt-supplied spring floods. However, the peaks were 

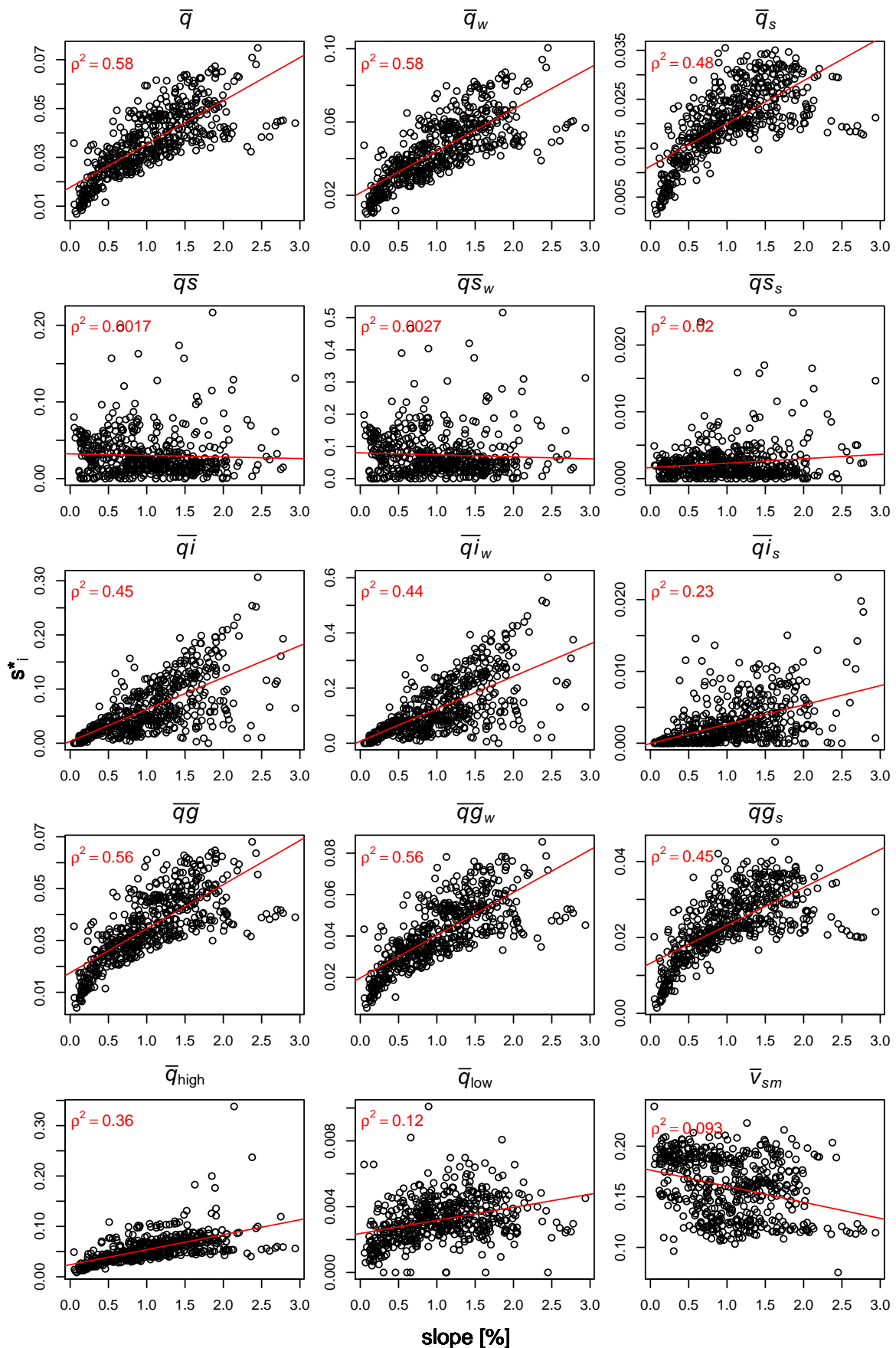

Figure 9. Relation between the slope and spatial sensitivity analysis results $\left(\stackrel{\star}{s_{i}}\right)$ quantified with different response functions. Explanation of the response functions is presented in Table 1.

underestimated by $8 \%$ of the observed value on average. The underestimations of peak discharges are possibly determined by the uncertainty of the rating curve. During the yearly spring floods, the measurement profile near the gauging station widens outside the riverbed and extends into the densely vegetated floodplain, where proper hydraulic measurements are very difficult. Nonetheless, the shape of the events resembled well the observed values, which can be an advantage of using observed SCF data instead of predicting snow cover in the model. This is supported by the comparison of the hydrograph (upper part of Fig. 7) with the timing of snowmelt and temperature rise above $0^{\circ} \mathrm{C}$ (lower part of Fig. 7), which shows a rapid discharge rise at the beginning of spring floods. Good results of using MODIS snow prod- 
ucts in other hydrological models have also been shown by Lee et al. (2005), Udnaes et al. (2007), Parajka and Blöschl (2008), Şorman et al. (2009), Tahir et al. (2011) and Berezowski et al. (2015). The model performed worse during periods of intensive summer storms. For these storms, a rapid discharge rise was simulated, which was not observed in reality. A possible reason for this low performance is the positively biased soil moisture prediction of the model during these periods.

\subsection{Spatial sensitivity analysis}

The global model output sensitivities $\left(\stackrel{\star}{s}_{i}\right)$ are calculated for a regular-structured grid (Fig. 8). This approach may be considered imperfect, as irregular, homogenous zonation (Younger et al., 2009) could more directly reference the sensitivity to spatial features of the model. Regular zonation used in this study was similar as in Stisen et al. (2011). This approach implies that the borders of spatial features do not resemble the zonation and the results are somewhat aggregated. An advantage of the structured grid lies, however, in broad comparability of different models; e.g. spatial sensitivity analysis in a study area modelled with different spatial discretization like hydrological response unit (SWAT) or grid cell (WetSpa) could be easily compared when using the structured grid. Moreover, an irregular approach would require much more zones if very fine spatial features were to be analyzed. This would require additional computational time, as the number of zones determines the number of parameters for the sensitivity analysis (see Sect. 4.3 for further discussion on this topic).

Computational time could be decreased if methods other than LH-OAT were used. Spatial sensitivity calculated based on a gradient method was presented by Hostache et al. (2010). Their results, although showing the importance of spatial sensitivity analysis, were calculated using a local method. Local methods do not properly handle the non-linear models (Turanyi and Rabitz, 2000). On the contrary, the method presented in this study results in a global sensitivity; i.e. it covers the whole parameter space and thus gives more insight into the model behaviour than a local method. There is still room for selecting other method for spatial sensitivity. Interesting results could be obtained when a variance-based method, like Sobol's (Sobol', 1993) would be used. Such an analysis would give additional information to LH-OAT on interactions between the model parameters.

\subsubsection{General relations of the spatial sensitivity analysis results with parameters maps}

The reason why most sensitivity maps calculated for different response functions (Fig. 8) were correlated with slope (Table 3 ) is because slope has a large impact on other hydraulic parameters (e.g. Manning coefficient) and also tunes values of depression storage and potential runoff coefficients (Liu and De Smedt, 2004).

A number of sensitivity maps were correlated with soiltexture-related parameters. These parameters have an influence on directing water that is stored as soil moisture and thus have general impact on groundwater, interflow and infiltrability. The soil-texture-related parameters have higher frequencies than the land-use-related parameters (cf. Tables 2 and 3). This means that soil texture is a clearly more important WetSpa input than land use with regard to the SCF sensitivity. The reason may be that the groundwater discharge accounts for $90 \%$ of the total simulated discharge and the parametrization of the groundwater processes is strongly dependent on soil properties in WetSpa.

Some of the WetSpa parameter maps have a $\rho^{2}$ not above the selected threshold for any of the sensitivity maps. In the case of the interception-related parameters the interception capacity is important in the summer half-year, when no SCF is present. A similar explanation holds for the root depth (an evapotranspiration-related parameter) which has a relatively negligible importance in the winter half-year. In the case of initial soil moisture content the explanation could be that it affects mostly the beginning of the simulation, i.e. the warmup period.

Parameters responsible for generating surface runoff also did not have $\rho^{2}$ above the selected threshold for any of the sensitivity maps. This is explained by the fact that the catchment is not urbanized and areas of high runoff coefficient and low depression storage are not frequent in this area. This situation is expected to be different for urbanized catchments, where the surface runoff would participate more in the total discharge than in this study area (Berezowski et al., 2012).

The frequency analyzed here is obviously dependent on the value of the $\rho^{2}$ threshold (in this case 0.40 ). The threshold is subjective, however, and allows discriminating between the high and low $\rho^{2}$. The selected threshold is justified by the fact that the $\rho^{2}=0.40$ is equivalent to the Pearson's correlation coefficient of 0.63 , which is generally considered as representing a strong correlation between variables. Nevertheless, the results should also be viewed in the scope of the $\rho^{2}$ values themselves.

The analysis of correlation between slope and sensitivity maps provided in more details in Fig. 9 shows that even when $\rho^{2}$ values are high (Table 3 ), the spatial sensitivity can be explained by a given parameter only in a certain range of its values, while for the remaining values the correlation is not that strong. This shows the complexity of the presented analysis. It has to be taken into account that the values presented in Table 3 show only the general relation with the sensitivity maps (Fig. 8), while different model behaviour is expected at different ranges of the analyzed values. 


\subsubsection{Spatial sensitivity in scope of the Biebrza River catchment functioning}

All the sensitivity maps calculated for the winter half-year response functions resemble the full-year response functions, both in the $\rho^{2}$ (Table 3) and in the spatial pattern (Fig. 8). This means that when looking at SCF sensitivity, the winter processes dominate the whole year. The reason for this lies in the fact that snowmelt water is routed mostly in winter and spring, while water routing in summer is only affected by remaining snowmelt water in soil moisture and groundwater reservoirs. A confirmation that SCF appears to influence summer half-year discharges more by groundwater than by surface runoff is the sensitivity for $\bar{q}_{\mathrm{s}}$, which has strong correlation with parameters related to groundwater flow. Nonetheless, the groundwater discharge dominates the total discharge in the model of Biebrza River catchment when looking at the similar results for the total discharge and groundwater discharge response functions. This is also confirmed in functioning of the Biebrza River catchment as described in literature (Pajnowska et al., 1984; Batelaan and Kuntohadi, 2002; Wassen et al., 2006; Chormański et al., 2011a).

This surface runoff response functions $\left(\overline{q s}\right.$ and $\left.\overline{q s}{ }_{\mathrm{w}}\right)$ sensitivity pattern may be related to the soil properties. As presented in Fig. 4, the south-eastern upland is dominated by loamy sand $\left(h \_\right.$con $=1.7 \times 10^{-5} \mathrm{~ms}^{-1}$ ), while soils with lower hydraulic conductivity are observed in the river valley (dominated by organic soils $h_{-}$con $=5.6 \times 10^{-6} \mathrm{~ms}^{-1}$ ) and the north-western upland (big share of sandy loam $h \_$con $=$ $\left.6.9 \times 10^{-6} \mathrm{~ms}^{-1}\right)$. The soil-sensitivity pattern is confirmed by the high $\rho^{2}$ with the hydraulic conductivity and weak but noticeable $\rho^{2}$ with the runoff coefficient. Thus, the infiltration ability and surface water routing have a considerable effect in explaining the SCF sensitivity for surface runoff. Another important role of surface runoff is revealed by relatively higher sensitivity of $\overline{q s}$ in the river valley than in most of the upland. This may be related to the fact that snowmelt in the Biebrza River valley is a considerable water source to spring floods and is transported as surface runoff (Chormański et al., 2011b).

The opposite pattern to $\overline{q s}$ is visible in $\overline{q i}$, what may be explained by the way the interflow is modelled in WetSpa. Interflow depends not only on the hydraulic conductivity (the key parameter for explaining sensitivity for $\overline{q s}$ ) but also on the slope $\left(\rho^{2}=0\right.$ for $\left.\overline{q s}\right)$, which is related to routing water in the subsoil and thus shows high $\rho^{2}$ with SCF sensitivity for $\overline{q i}$ and $\overline{q i}_{\mathrm{w}}$ (Table 3 ).

No $\rho^{2} \geqslant 0.40$ are found for the SCF sensitivity for $\overline{q i}_{\mathrm{s}}$ (Table 3). In this case, the role of the parameters is limited. This is probably because most of the interflow water that could be related to SCF produced discharge during winter half-year. The highest $\rho^{2}$, similar to $\overline{q i}$ and $\overline{q i}_{\mathrm{w}}$, is found with the slope, which can also be easily linked by similarity of spatial patterns with the SCF sensitivity map (cf. Figs. 2 and 8).
Similarly, no $\rho^{2} \geqslant 0.40$ are found for the SCF sensitivity for $\bar{q}_{\text {low }}$ and $\bar{q}_{\text {high }}$ (Table 3). Thus there are other sources of variance in the SCF sensitivity for these response functions which do not originate directly in the parameter maps. Only a low but noticeable $\rho^{2}$ is found between $\bar{q}_{\text {high }}$ and the slope, indicating a link with runoff generation in WetSpa.

The pattern of $\bar{q}_{\text {low }}$ may be related to extreme groundwater deficits to which mineral soils in the uplands have a higher contribution than organic saturated soils in the valley (porosity has low but noticeable $\rho^{2}$ ). The spatial pattern of soil moisture in the Biebrza River valley presented by Dabrowska-Zielińska et al. (2009) partially confirms the spatial sensitivity analysis results presented in this paper.

\subsubsection{Mean snowmelt response function}

A completely different pattern than for the other response functions is presented by SCF sensitivity for $\bar{v}_{\text {sm }}$ (Fig. 8). According to Eq. (1), $v_{\mathrm{sm}}$ in a model grid cell (and thus $\bar{v}_{\mathrm{sm}}$ in the entire catchment) is calculated based on temperature and precipitation and then adjusted by SCF. As a result, the sensitivity for $\bar{v}_{\mathrm{sm}}$ corresponds to the spatial pattern of the mean yearly temperature averaged in the Thiessen polygons, while the yearly sum of precipitation in the Thiessen polygons is less influential (Table 3). The pattern of SCF is not visible, because in this sensitivity analysis the SCF values in Eq. (1) come from the random LH-OAT sampling. The reason that $\rho^{2}$ between $\bar{v}_{\text {sm }}$ and temperature and precipitation is lower than 1.00 is because the values are aggregated in time and space and lose some of the variance important for the relation.

\subsection{Computational constraints}

The total computation time, a product of simulation time and number of required runs, is a limitation of the applicability of this method and is similar to in all methods requiring a large number of model runs to achieve the desired output. This was also the case in this study; as WetSpa required about $1 \mathrm{~min}$ for a single run, the total time for 52500 simulations was about 36.5 days. The advantage of any random-samplingbased sensitivity analysis method (including LH-OAT) is that it is easily parallelized, i.e. the LH-OAT samples are obtained before the simulations and the model runs are divided over a number of processors or computers.

One could, however, consider decreasing the number of zones $(n)$ in which the input data are perturbed or the number of LH samples $(p)$ to receive the results faster. The latter implies that the LH-OAT method may not converge (Nossent and Bauwens, 2012). Thus, it seems more reasonable to decrease the number of zones and be satisfied with results at lower spatial resolution. 


\subsection{Applicability of the spatial sensitivity analysis}

The analyses conducted in this case study are both a validation and an example application of the spatial sensitivity analysis method. The further potential use of this method could be twofold: for generic sensitivity analysis and for a catchment change scenario analysis.

The generic sensitivity analysis would be similar to the presented approach in this paper. The maps (e.g. Fig. 8) would show zones of the catchment with high or low sensitivity. The correlation analysis as in Table 3 would show the parameters explaining the sensitivity pattern which thus require more attention during the parametrization. This would require possibly denser field sampling of the correlated parameters additional to the data subjected to sensitivity analysis or obtaining the data from a source with less uncertainty; as a result, the prediction uncertainty should be decreased. Additionally, the detailed scatter plots of parameters against response functions (e.g. Fig. 9) would show which data ranges of the parameters are the most responsible for the spatial sensitivity pattern. In contrast, the "standard" sensitivity analysis is performed for global parameters which usually are not spatially distributed or are semi-distributed (i.e. grouped to few categories with the same values; e.g. Ayvaz, 2013).

The catchment change scenario analysis was not investigated in this paper but is a possible application of the presented spatial sensitivity analysis method. In such an analysis instead of SCF input time series the LH-OAT sampling would be done for e.g. different land covers proportions in the catchment zones. The output of such an analysis would be sensitivity of the zones to changes in land cover and could be used as e.g. a decision support for urban development.

\section{Conclusions}

With increasing spatial data availability for distributed hydrological modelling a need appears for a methodology for sensitivity analysis of the spatial data. Such a methodology should point to zones of the study area where the sensitivity of a model spatial input to output is higher or lower and should relate these patterns to the processes simulated by the model. In order to answer these needs this paper presents an application of the LH-OAT sensitivity analysis to the WetSpa model of the Biebrza River catchment. Unlike a standard sensitivity analysis of global model parameters, a spatial approach is presented in this study. The catchment is divided into regular snow grid cells or zones in which sensitivity of SCF as input data was evaluated. The aim of this study was to present an approach for using sensitivity analysis for spatial input data and to show that the WetSpa model is sensitive to spatial input data. Moreover, it was intended to show that the spatial sensitivity results are related to physical parameters used in the model.
The spatial approach of the LH-OAT sensitivity analysis results in spatial maps presenting areas of relatively higher and lower sensitivity. In order to extend the analysis, the sensitivity analysis was repeated with different response functions. Most of the sensitivity analysis results were similar for the whole year and winter half-year response functions. Moreover, the sensitivity obtained for the mean discharge response function was very similar to the sensitivity analysis for the mean groundwater discharge response function. Hence, the model behaviour related to snow processes is dominated by winter half-year and groundwater processes, which is in agreement with the Biebrza River spring flood regime with a dominant share of groundwater discharge. Another important finding was that SCF sensitivity was high in snow zones in the river valley under the winter half-year surface runoff response function. This is in agreement with the observation that the snowmelt in the river valley is a considerable surface runoff source to spring floods.

In this case study, the spatial patterns of SCF sensitivity could, for most of the response functions, easily be interpreted by co-occurrence of different landscape features like upland and river valley. However, for some of the response functions a straightforward interpretation was impossible. A successful approach to interpreting the patterns was performed by analysing the values of coefficients of determination between the physical model parameters and the SCF sensitivity. The spatial pattern of the sensitivity for different response functions, obtained from these results, is related to different spatial parameters and to different physical processes simulated by the model. The parameters which had a strong correlation with the SCF sensitivity for most of the response functions were slope and soil-related parameters. The potential runoff coefficient and depression storage were important for only a few response functions, because the catchment is not urbanized. Temperature, which directly influences the snowmelt generation in the WetSpa model, shows a strong correlation only with the mean snowmelt response function. It is important to mention that the spatial sensitivity quantified with several response functions was correlated to more than one spatial parameter. This shows the importance of the links between the parameters which were revealed by this spatially distributed analysis.

In summary, a spatial approach of sensitivity analysis can be performed with the LH-OAT algorithm, as presented in the results of this paper, and the SCF is spatially sensitive in the WetSpa model. The pattern of spatial sensitivity is related to spatially distributed physical parameters, and the results are confirmed by a priori scientific understanding of the Biebrza River catchment functioning. The spatial sensitivity maps can by used to highlight areas which require better attention during the parametrization and to show which spatial parameters have influence on the analyzed phenomena: in this case, the snow-related processes.

In future work, other input time series or input parameters should be evaluated in a spatial analysis. It would also be in- 
teresting to compare spatial sensitivity of the same input data with other models, e.g. TOPMODEL or SWAT. Finally, since spatial SCF is sensitive in WetSpa, other sources of these input data should be tested in the model.

Acknowledgements. We wish to thank two anonymous reviewers for their comments and suggestions that improved this work. We also acknowledge Ignacy Kardel for sharing the sources for the soil map used in this study. The first author acknowledges the Flemish government for supporting his research visit to the Vrije Universiteit Brussel. The hydrometeorological data were provided by Institute of Meteorology and Water Management National Research Institute (IMGW).

Edited by: A. Gelfan

\section{References}

Abbott, M., Bathurst, J., Cunge, J., O’Connell, P., and Rasmussen, J.: An introduction to the European Hydrological System Systeme Hydrologique Europeen, "SHE", 2: Structure of a physically-based, distributed modelling system, J. Hydrol., 87, 61-77, 1986.

Ampe, E., Vanhamel, I., Salvadore, E., Dams, J., Bashir, I., Demarchi, L., Chan, J., Sahli, H., Canters, F., and Batelaan, O.: Impact of Urban Land-Cover Classification on Groundwater Recharge Uncertainty, Selected Topics in Applied Earth Observations and Remote Sensing, IEEE J., 5, 1859-1867, 2012.

Ayvaz, M. T.: A linked simulation-optimization model for simultaneously estimating the Manning's surface roughness values and their parameter structures in shallow water flows, J. Hydrol., 500, 183-199, 2013.

Batelaan, O. and De Smedt, F.: GIS-based recharge estimation by coupling surface-subsurface water balances, J. Hydrol., 337, 337-355, 2007.

Batelaan, O. and Kuntohadi, T.: Development and application of a groundwater model for the Upper Biebrza River Basin, Annals of Warsaw Agricultural University-SGGW, Land Reclamation, 33, 57-69, 2002.

Bavera, D., De Michele, C., Pepe, M., and Rampini, A.: Melted snow volume control in the snowmelt runoff model using a snow water equivalent statistically based model, Hydrol. Process., 26, 3405-3415, 2012.

Berezowski, T., Chormański, J., Batelaan, O., Canters, F., and Van de Voorde, T.: Impact of remotely sensed land-cover proportions on urban runoff prediction, Int. J. Appl. Earth Observ. Geoinform., 16, 54-65, 2012.

Berezowski, T., Chormański, J., and Batelaan, O.: Skill of remote sensing snow products for distributed runoff prediction, J. Hydrol., 524, 718-732, 2015.

Beven, K. and Freer, J.: A dynamic TOPMODEL, Hydrol. Process., 15, 1993-2011, 2001.

Beven, K., Lamb, R., Quinn, P., Romanowicz, R., Freer, J., and Singh, V.: Computer models of watershed hydrology, Chap. Topmodel, 627-668, Water Resources Publications, Colorado, USA, 1995.
Butt, M. J. and Bilal, M.: Application of snowmelt runoff model for water resource management, Hydrol. Process., 25, 3735-3747, 2011.

Chormański, J.: Analysis of urbanization impact on changes in river discharge - a case study of the Biała river catchment, Studia Geotechn. Mechan., 34, 19-32, 2012.

Chormański, J. and Batelaan, O.: Application of the WetSpa distributed hydrological model for catchment with significant contribution of organic soil. Upper Biebrza case study, Annals of Warsaw University of Life Sciences-SGGW, Land Reclamation, 43, 25-35, 2011.

Chormański, J. and Michałowski, R.: Hydrological catchment model WetSpa-SGGW integrated with a calculation module in ArcGIS environment, Sci. Rev. Eng. Environ. Sci., 53, 196-206, 2011 (in Polish).

Chormański, J., Van de Voorde, T., De Roeck, T., Batelaan, O., and Canters, F.: Improving Distributed Runoff Prediction in Urbanized Catchments with Remote Sensing based Estimates of Impervious Surface Cover, Sensors, 8, 910-932, 2008.

Chormański, J., Berezowski, T., Okruszko, T., and Ignar, S.: Contemporary problems of management and environmental protection. Vol. 7 - Issue of Landscape Conservation and Water Management in Rural Areas, chap. Hydrography and hydrology of the upper Biebrza basin, 175-203, Uniwersytet Warminsko Mazurski, Olsztyn, Poland, 2011a.

Chormański, J., Okruszko, T., Ignar, S., Batelaan, O., Rebel, K., and Wassen, M.: Flood mapping with remote sensing and hydrochemistry: a new method to distinguish the origin of flood water during floods, Ecol. Eng., 37, 1334-1349, 2011b.

Commission of the European Communities: CORINE Landcover, available at: http://www.eea.europa.eu/publications/ COR0-landcover, last access: 1 November 2013.

Dabrowska-Zielińska, K., Gruszczyńska, M., Lewiński, S., Hościło, A., and Bojanowski, J.: Application of remote and in situ information to the management of wetlands in Poland, J. Environ. Manage., 90, 2261-2269, 2009.

Dams, J., Dujardin, J., Reggers, R., Bashir, I., Canters, F., and Batelaan, O.: Mapping impervious surface change from remote sensing for hydrological modeling, J. Hydrol., 485, 84-95, 2013.

Demarchi, L., Canters, F., Chan, J. C.-W., Ampe, E., and Batelaan, O.: Use of land-cover fractions derived from MESMA for urban water balance calculation, in: Geoscience and Remote Sensing Symposium (IGARSS), 2012 IEEE International, 1594-1597, IEEE, 2012.

De Smedt, F., Liu, Y. B., and Gebremeskel, S.: Risk Analysis II, chap. Hydrologic modeling on a catchment scale using GIS and remote sensed land use information, 295-304, WTI press, Southampton, Boston, 2000.

Duan, Q., Gupta, V., and Sorooshian, S.: Shuffled complex evolution approach for effective and efficient global minimization, J. Optimiz. Theory Appl., 76, 501-521, 1993.

Dujardin, J., Batelaan, O., Canters, F., Boel, S., Anibas, C., and Bronders, J.: Improving surface-subsurface water budgeting using high resolution satellite imagery applied on a brownfield, Sci. Total Enviro., 409, 800-809, 2011.

Fu, S., Sonnenborg, T. O., Jensen, K. H., and He, X.: Impact of Precipitation Spatial Resolution on the Hydrological Response of an Integrated Distributed Water Resources Model, Vadose Zone J., 10, 25-36, 2011. 
Hall, D. K., Riggs, G. A., and Salomonson, V. V.: MODIS/Terra Snow Cover Daily L3 Global 500m Grid V005, Dataset used 2007-2009, digital media, 2006.

Hostache, R., Lai, X., Monnier, J., and Puech, C.: Assimilation of spatially distributed water levels into a shallow-water flood model. Part II: Use of a remote sensing image of Mosel River, J. Hydrol., 390, 257-268, 2010.

Klein, A. G., Hall, D. K., and Riggs, G. A.: Improving snow cover mapping in forests through the use of a canopy reflectance model, Hydrol. Process., 12, 1723-1744, 1998.

Lee, S., Klein, A. G., and Over, T. M.: A comparison of MODIS and NOHRSC snow-cover products for simulating streamflow using the Snowmelt Runoff Model, Hydrol. Process., 19, 2951-2972, 2005.

Li, X. and Williams, M. W.: Snowmelt runoff modelling in an arid mountain watershed, Tarim Basin, China, Hydrol. Process., 22, 3931-3940, 2008.

Liston, G. E.: Interrelationships among Snow Distribution, Snowmelt, and Snow Cover Depletion: Implications for Atmospheric, Hydrologic, and Ecologic Modeling, J. Appl. Meteorol., 38, 1474-1487, 1999.

Liu, Y. B. and De Smedt, F.: WetSpa Extension, A GIS-based Hydrologic Model for Flood Prediction and Watershed Management, Department of Hydrology and Hydraulic Engineering, Vrije Universiteit Brussel, pp. 66, 2004.

Liu, Y. B., Gebremeskel, S., De Smedt, F., Hoffmann, L., and Pfister, L.: A diffusive transport approach for flow routing in GISbased flood modeling, J. Hydrol., 283, 91-106, 2003.

Maciorowski, G., Mirski, P., Kardel, I., Stelmaszczyk, M., Miroslaw-Swiaatek, D., Chormański, J., and Okruszko, T.: Water regime as a key factor differentiating habitats of spotted eagles Aquila clanga and Aquila pomarina in Biebrza Valley (NE Poland), Bird Study, 62, 120-125, 2014.

Martinec, J.: Snowmelt - Runoff Model For Stream Flow Forecasts, Nordic Hydrol. 6, 145-154, 1975.

McKay, M., Beckman, R., and Conover, W.: Comparison of Three Methods for Selecting Values of Input Variables in the Analysis of Output From a Computer Code, Technometrics, 21, 239-245, 1979.

Mioduszewski, W., Querner, E. P., Slesicka, A., and Zdanowicz, A.: Basis of water management in the Valley of Lower Biebrza River, J. Water Land Develop., 49-61, 2004.

Morris, M. D.: Factorial Sampling Plans For Preliminary Computational Experiments, Technometrics, 33, 161-174, 1991.

Nash, J. and Sutcliffe, J.: River flow forecasting through conceptual models part I - A discussion of principles, J. Hydrol., 10, 282 290, 1970

Nossent, J.: Sensitivity and uncertainty analysis in view of the parameter estimation of a SWAT model of the river Kleine Nete, Belgium, PhD thesis, Vrije Universiteit Brussel, 2012.

Nossent, J. and Bauwens, W.: Multi-variable sensitivity and identifiability analysis for a complex environmental model in view of integrated water quantity and water quality modeling, Water Sci. Technol., 65, 539-549, 2012.

Nossent, J., Tolessa Leta, O., and Bauwens, W.: Assessing the convergence of a Morris-like screening method for a complex environmental model, in: 7th International Conference on Sensitivity Analysis of Model Output, Oral presentations Proceedings, 2013.
Obled, C., Wendling, J., and Beven, K.: The Sensitivity of Hydrological Models To Spatial Rainfall Patterns - An Evaluation Using Observed Data, J. Hydrol., 159, 305-333, 1994.

Pajnowska, H., Poźniak, R., and Wiencław, E.: Groundwaters of the Biebrza Valley, Polish Ecol. Stud., 10, 301-311, 1984.

Parajka, J. and Blöschl, G.: The value of MODIS snow cover data in validating and calibrating conceptual hydrologic models, J. Hydrol., 358, 240-258, 2008.

Poelmans, L., Van Rompaey, A., and Batelaan, O.: Coupling urban expansion models and hydrological models: How important are spatial patterns?, Land Use Pol., 27, 965-975, 2010.

Querner, E.: Description and application of the combined surface and groundwater flow model MOGROW, J. Hydrol., 192, 158$188,1997$.

R Development Core Team: R: A Language and Environment for Statistical Computing, R Foundation for Statistical Computing, Vienna, Austria, ISBN 3-900051-07-0, 2013.

Rojek, M.: Evaporation from free water surface 1951-2000, Map in scale $1: 2500$ 000, Tech. Rep., IMGW, Warsaw, Poland, 2000.

Sælthun, N.: The Nordic HBV Model, Norwegian Water Resources and Energy Administration Publication, Oslo, Norway, 7, 1996.

Safari, A., De Smedt, F., and Moreda, F.: WetSpa model application in the Distributed Model Intercomparison Project (DMIP2), J. Hydrol., 418-419, 78-89, 2012.

Saltelli, A.: Sensitivity analysis for importance assessment, Risk Anal., 22, 579-590, 2002.

Schuurmans, J. M. and Bierkens, M. F. P.: Effect of spatial distribution of daily rainfall on interior catchment response of a distributed hydrological model, Hydrol. Earth Syst. Sci., 11, 677693, doi:10.5194/hess-11-677-2007, 2007.

Sobol', I.: Sensitivity analysis for non-linear mathematical models, Math. Model. Comput. Experiment, 1, 407-414, 1993.

Şorman, A. A., Şensoy, A., Tekeli, A. E., Şorman, A. U., and Akyürek, Z.: Modelling and forecasting snowmelt runoff process using the HBV model in the eastern part of Turkey, Hydrol. Process., 23, 1031-1040, 2009.

Stachý, J.: Hydrological Atlas of Poland, Vol. 1, Wydawnictwo Geologiczne, Warsaw, Poland, 1987 (in polish with english translation).

Stisen, S., McCabe, M. F., Refsgaard, J. C., Lerer, S., and Butts, M. B.: Model parameter analysis using remotely sensed pattern information in a multi-constraint framework, J. Hydrol., 409, 337-349, 2011.

Tahir, A. A., Chevallier, P., Arnaud, Y., Neppel, L., and Ahmad, B.: Modeling snowmelt-runoff under climate scenarios in the Hunza River basin, Karakoram Range, Northern Pakistan, J. Hydrol., 409, 104-117, 2011.

Tekeli, A. E., Akyürek, Z., Arda Şorman, A., Şensoy, A., and Unal Şorman, A.: Using MODIS snow cover maps in modeling snowmelt runoff process in the eastern part of Turkey, Remote Sens. Environ., 97, 216-230, 2005.

Turanyi, T. and Rabitz, H.: Sensitivity Analysis, Chap. Local Methods, Wiley, Chichester, 2000.

Udnaes, H. C., Alfnes, E., and Andreassen, L. M.: Improving runoff modelling using satellite-derived snow covered area?, Nordic Hydrology, 38, 21-32, 2007.

van Griensven, A., Meixner, T., Grunwald, S., Bishop, T., Diluzio, M., and Srinivasan, R.: A global sensitivity analysis tool for the 
parameters of multi-variable catchment models, J. Hydrol., 324, 10-23, 2006.

Verbeiren, B., Van De Voorde, T., Canters, F., Binard, M., Cornet, Y., and Batelaan, O.: Assessing urbanisation effects on rainfallrunoff using a remote sensing supported modelling strategy, Int. J. Appl. Earth Observ. Geoinform., 21, 92-102, 2013.

Wang, Z.-M., Batelaan, O., and De Smedt, F.: A distributed model for water and energy transfer between soil, plants and atmosphere (WetSpa), Phys. Chem. Earth, 21, 189-193, 1996.

Wassen, M. J., Okruszko, T., Kardel, I., Chormanski, J., Swiatek, D., Mioduszewski, W., Bleuten, W., Querner, E. P., El Kahloun, M., Batelaan, O., and Meire, P.: Eco-hydrological functioning of the Biebrza wetlands: Lessons for the conservation and restoration of deteriorated wetlands, Wetlands: Functioning, Biodivers. Conserv. Restor., 191, 285-310, 2006.
Yang, J., Liu, Y., Yang, W., and Chen, Y.: Multi-Objective Sensitivity Analysis of a Fully Distributed Hydrologic Model WetSpa, Water Resour. Manage., 26, 109-128, 2012.

Younger, P. M., Freer, J. E., and Beven, K. J.: Detecting the effects of spatial variability of rainfall on hydrological modelling within an uncertainty analysis framework, Hydrol. Process., 23, 19882003, 2009.

Zeinivand, H. and De Smedt, F.: Prediction of snowmelt floods with a distributed hydrological model using a physical snow mass and energy balance approach, Nat. Hazards, 54, 451-468, 2010. 